\title{
PROCESAMIENTO DE METALES DURANTE EL HORIZONTE MEDIO EN EL ALTIPLANO SURANDINO (ESCARAMAYU, PULACAYO, POTOSÍ, BOLIVIA)
}

\section{METAL PROCESSING DURING THE MIDDLE HORIZON IN THE SOUTH ANDEAN ALTIPLANO IESCARAMAYU, PULACAYO, POTOSÍ, BOLIVIA}

\author{
Heather lechtman *, Pablo Cruz * *, \\ ANDREW MACFARLANE* **, \\ SIDNEY CARTER ****
}

\begin{abstract}
En este trabajo se presentan y se analizan los resultados alcanzados en el sector metalúrgico del sitio Pulac 050 (Escaramayu, Pulacayo, Bolivia). Los estudios desarrollados en el sector han puesto en evidencia un complejo de cuatro hornos metalúrgicos, los cuales se encuentran espacialmente asociados con un conjunto de recintos fechados en el Horizonte Medio. Restos de varios materiales incluyendo escorias, metales y minerales fueron encontrados junto a los hornos. Los análisis de isótopo de plomo de estos materiales sugieren fuertemente que la mena fundida en el sitio fue obtenida del depósito polimetálico de plomo, plata, cobre y zinc, de Pulacayo. Tres de los hornos parecen haber sido utilizados para fundir menas metálicas; mientras que el cuarto horno se usó para refinar, quizás, el metal impuro contenido dentro de crisoles de cerámica.

Palabras clave: metalurgia, hornos de extracción y refinación, Horizonte Medio
\end{abstract}

In this article we present and analyze the results obtained to date in the metallurgical sector of site Pulac 050 (Escaramayu, Pulacayo, Bolivia). Thus far the studies conducted in this sector present evidence of a complex of four metallurgical furnaces that are spatially associated with a group of enclosures at the site that have been dated to the Middle Horizon. The remains of various materials including slags, metals, and minerals are found together with the furnaces. Lead isotope analyses of these materials suggest strongly that the ore smelted at the site was obtained from the complex lead, silver, copper, zinc deposit at Pulacayo. Three of the furnaces appear to have been used to smelt ore; the fourth furnace likely refined impure metal contained in ceramic crucibles.

Key words: metallurgy, smelting and refining furnaces, Middle Horizon

* Heather Lechtman, Department of Materials Science and Engineering, Massachusetts Institute of Technology, 77 Massachusetts Ave, Room 8-437, Cambridge, MA 02139, USA, email: lechtman@mit.edu

** Pablo Cruz, Parque Nacional Calilegua, San Lorenzo s/n, Calilegua, Jujuy, Bolivia, email: saxrapablo@gmail.com

***: Andrew Macfarlane, Department of Earth Sciences, Florida International University, 11200 SW $8^{\text {th }}$ Street, University Park, Miami, FL 33199, USA, email: macfarlane@fiu.edu

****: Sidney Carter, Center for Materials Research in Archaeology and Ethnology, Massachusetts Institute of Technology, 77 Massachusetts Ave, Room 16-539, Cambridge, MA 02139, USA, email: swcarter@mit.edu

\section{INTRODUCCIÓN}

El área de estudio del proyecto de investigación en curso, del que surge este trabajo, comprende las comunidades de Escara y Pulacayo, las cuales se localizan en la región inmediatamente al este del salar de Uyuni (fig. 1). Se trata de una región con un ambiente típico de puna, entre los 4.200 y $3.800 \mathrm{msnm}$, que alterna altas cumbres, colinas ondulantes, mesetas de altura y vastos ríos estacionales. La región tuvo un desarrollo significativo durante la primera mitad del siglo xx en torno a las importantes minas de Pulacayo y Huanchaca donde fueron explotados, de manera intensiva, complejos de plomo, plata, cobre y zinc. Actualmente, Pulacayo es un campamento minero casi abandonado, a no ser por un centenar de trabajadores que continúa trabajando sus vetas. Junto a la minería, la cría de llamas y el incipiente cultivo de la quínoa constituyen las principales actividades económicas tradicionales y, fuera de estas, la industria del turismo centralizada en el enclave de Uyuni.

A mediados de la década de 1990, un joven de la región descubrió y excavó una pequeña cueva funeraria hasta ese momento intacta, ubicada dentro de un afloramiento de rocas sedimentarias. Del interior de la 


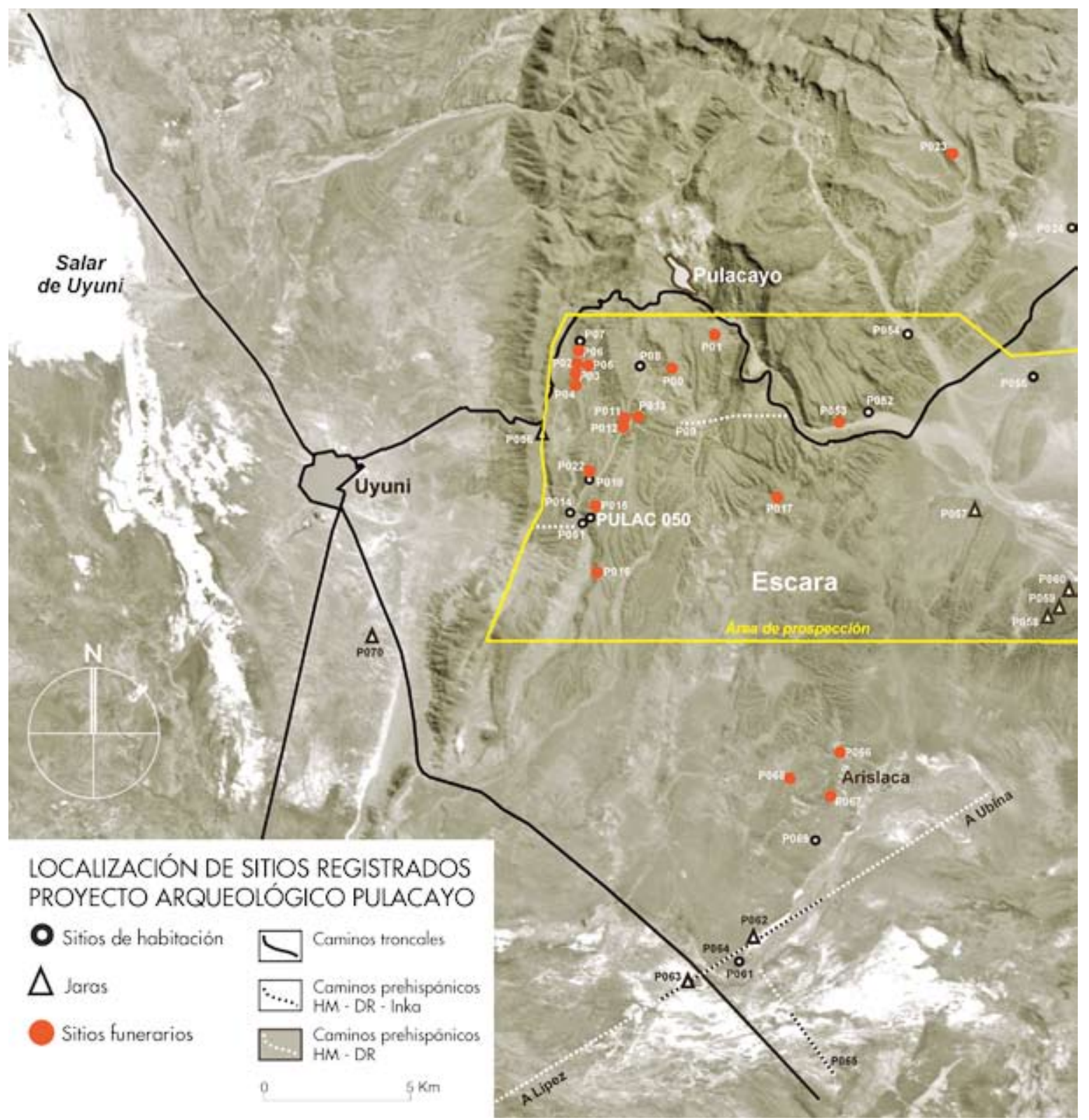

Figura 1. Carta satélite del área de estudio con localización de los sitios registrados.

Figure 1. Satellite map of the area of study identifying registered sites.

cueva se exhumaron cinco individuos, quienes fueron depositados con varios objetos y bienes de prestigio, entre ellos dos unkus, gorros de lana con cuatro puntas, varios artefactos de bronce estannífero y un "brazal" (fig. 2) del mismo material. ${ }^{1}$ Muchos de los objetos de la tumba, como el unku que lleva el motivo del "sacrificador" (fig. 3) y los gorros de cuatro puntas, son de estilo y fabricación Tiwanaku, y nos proporcionan una fecha relativa en el Horizonte Medio para este contexto. Un análisis de $\mathrm{C}^{14}$ realizado sobre un fragmento de hueso procedente de uno de los individuos de esta tumba corrobora esta cronología arrojando un resultado de $1250+/-40$ años AP, lo cual nos da una fecha calibrada situada entre los años 674 y 874 de nuestra Era. ${ }^{2}$ Sin embargo, la región fue considerada como un desierto humano donde la altura y el clima rudo dificultaron las actividades económicas de subsistencia (Cruz 2010). Hasta hace poco tiempo, los restos de los individuos hallados en la "tumba de Pulacayo" fueron interpretados como pertenecientes a viajeros tiwanakotas, muertos en 

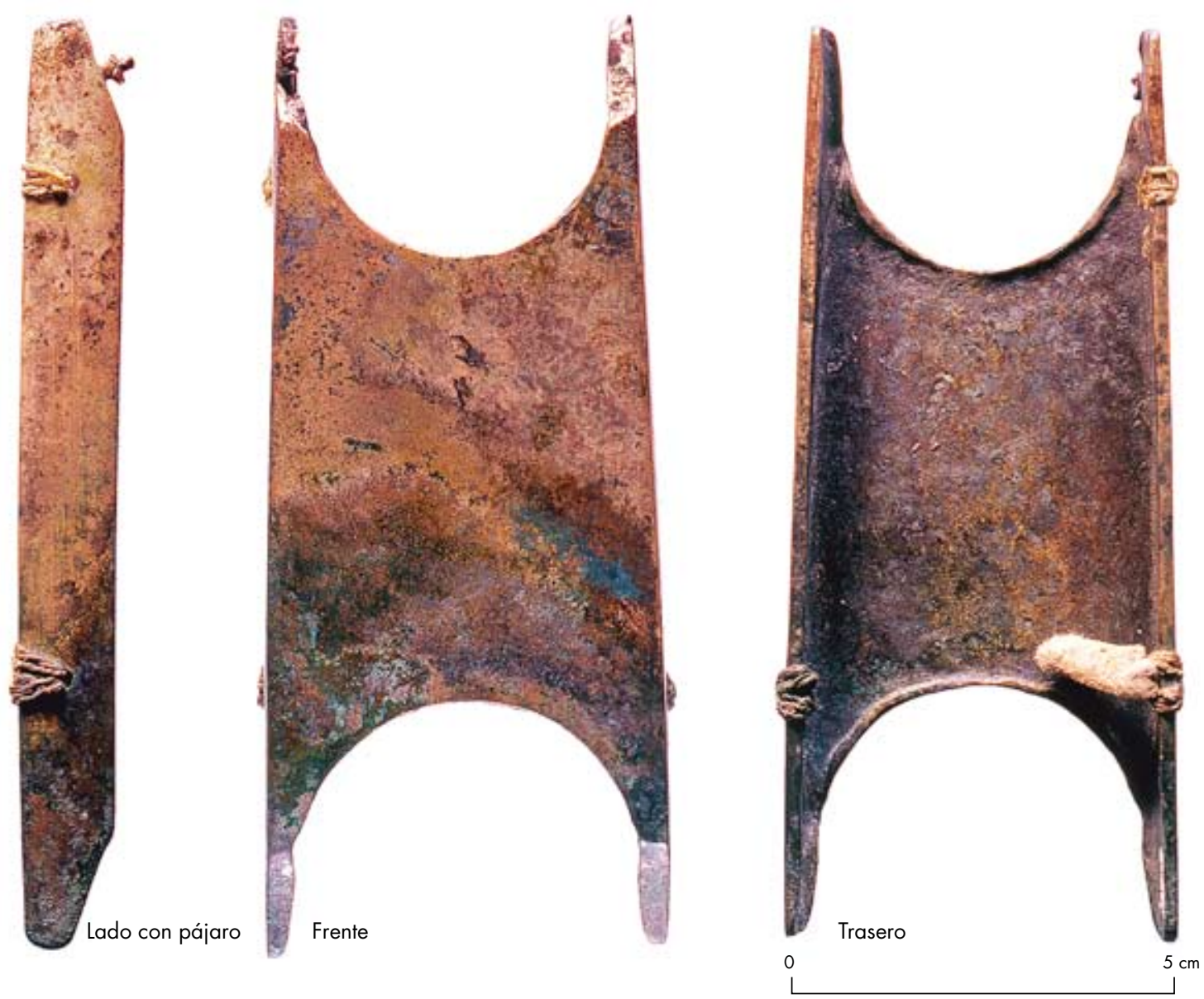

Figura 2. Fotografía del brazal de bronce hallado en la "Cueva de Pulacayo". Figure 2. Photograph of a bronze arm band found in the "Cueva de Pulacayo."

desplazamiento desde o hacia San Pedro de Atacama (Céspedes 2000 Ms; Costa Junqueira 2003).

En el año 2005, basado en las primeras evidencias proporcionadas por el contenido de la cueva de Pulacayo, se inicia, desde ASUR (Antropólogos del Sur Andino), un proyecto de investigación destinado a registrar e interpretar la ocupación humana de la región, así como sus posibles vínculos con las sociedades del norte (Tiwanaku) y del oeste (San Pedro de Atacama) (fig. 4). El proyecto comenzó con una primera etapa de reconocimiento y prospecciones abarcando un área aproximada de $250 \mathrm{~km}^{2}$ : desde el borde oriental del salar de Uyuni (oeste) hasta el río Huanchaca (este), y desde la localidad de Colchani (norte) hasta el río Arislaca (sur) (ver fig. 1). Como resultado de esta primera etapa se obtuvo un registro de 19 sitios funerarios colectivos e individuales, 12 sitios de habitación, ocho jaras o recintos (campamentos caravaneros) y tres caminos asociados con jaras (Cruz 2010). Sólo en tres sitios de habitación -Pulac 050, Pulac 051 y Pulac 052- se registraron evidencias de actividades metalúrgicas. ${ }^{3}$ Varios sitios funerarios y el sitio Pulac 050 fueron objeto de excavaciones arqueológicas.

\section{EL SITIO PULAC 050}

Centramos este estudio en uno de estos sitios, Pulac 050, que se distingue tanto por presentar un conjunto de recintos rectangulares como por albergar un sector asociado con la producción metalúrgica (fig. 5). Es importante recalcar que las investigaciones se continúan desarrollando en el sitio, y se espera que las nuevas informaciones que se obtendrán amplíen sustancialmente el estado de la cuestión aquí presentado. El sitio se encuentra sobre los $3.850 \mathrm{msnm}$, a unos $10 \mathrm{~km}$ lineales al sur del campamento minero de Pulacayo, sobre la margen este del río Escaramayu, cuyo caudal 


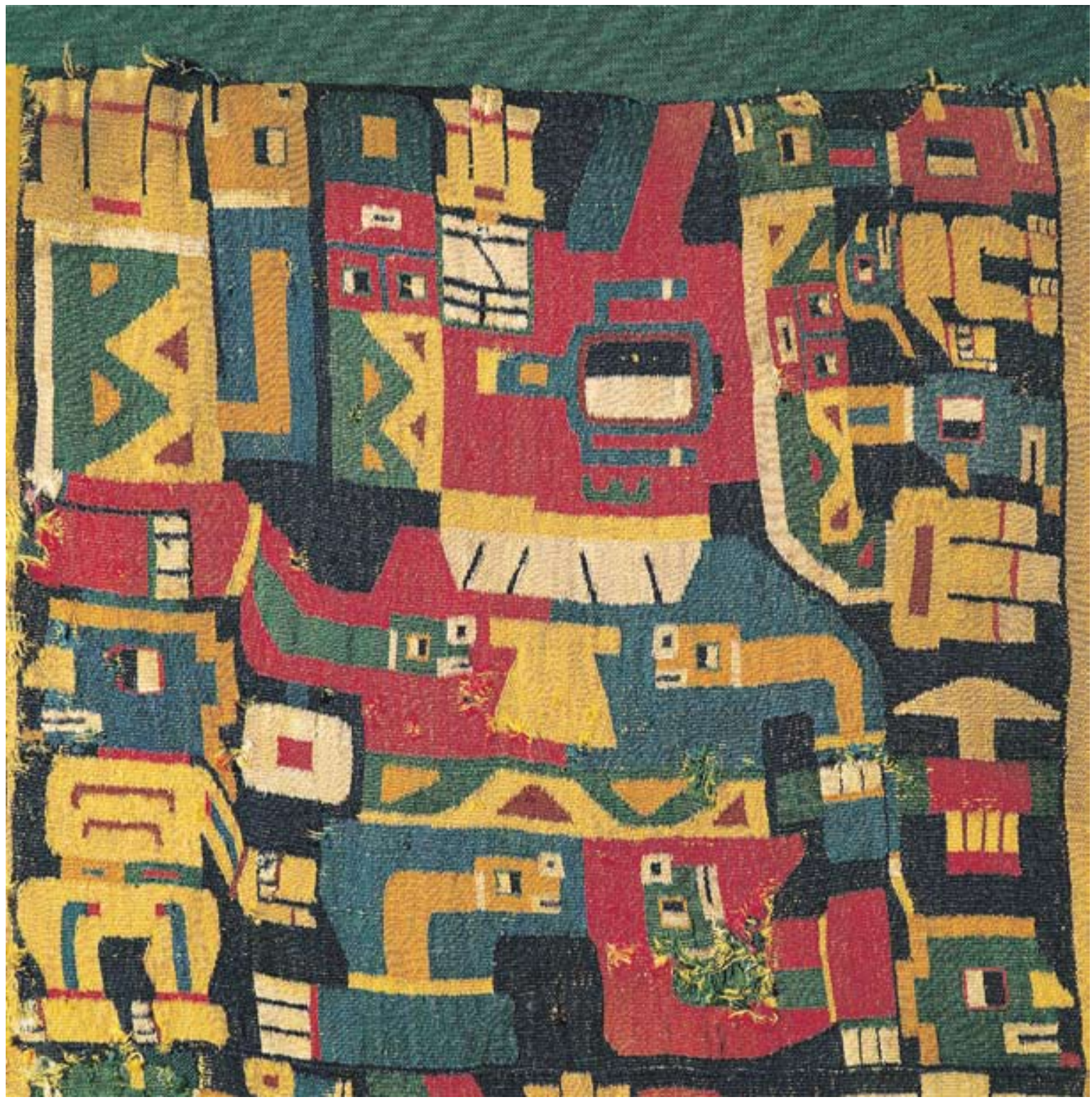

Figura 3. Detalle del unku de Estilo Tiwanaku, con representación del sacrificador, hallado en la "Cueva de Pulacayo" (tomado de Berenguer 2000: 87).

Figure 3. Detail of a Tiwanaku-style unku tunic with a representation of the sacrificer figure, discovered in the "Cueva de Pulacayo" (taken from Berenguer 2000: 87).

es estacional. Dados los rasgos hallados en los dos recintos excavados (fig. 6), localizados a $60 \mathrm{~m}$ del sector metalúrgico -numerosas piletas y banquetas (R2, estructuras 5, 6 y 7), estructuras de combustión (R1, estructuras 1, 2 y 3; R2, estructura 8) y una pequeña estructura de almacenamiento subterránea asociada con concentraciones de óxido de cobre (R1, estructura 4)-, y la diversidad de los artefactos encontrados en ellos: planos de trabajo, martillos y alisadores líticos bien labrados, bloques de piedra pómez formatizados (fig. 7), análogos de aquellos observados en el sector metalúrgico, uno de nosotros ha considerado que estas estructuras funcionaron como talleres artesanales asociados con el trabajo del metal (Cruz 2010). Dos fechados AMS fueron obtenidos con muestras de carbón recogidas en el recinto $\mathrm{R} 1$. El primero de ellos, tomado de una muestra de fogón, arrojó un resultado de 1330+/-83 años AP, lo cual proporciona una fecha calibrada de 563-889 DC. ${ }^{4}$ El segundo fechado, cuya muestra de carbón fue tomada dentro de una pequeña 


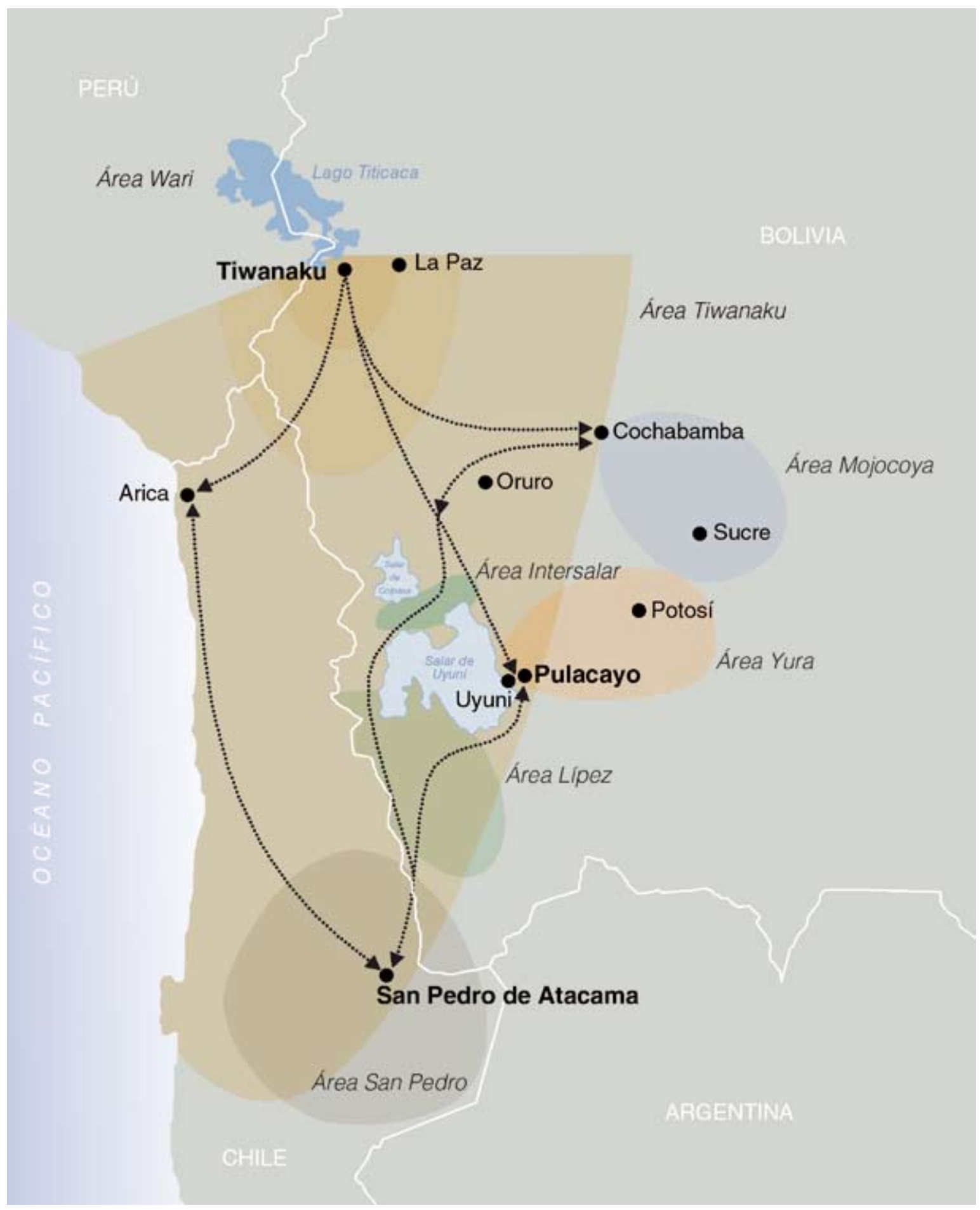

Figura 4. Mapa con las vinculaciones de Pulacayo (área Yura) en la macrorregión.

Figure 4. Map showing the links between Pulacayo (Yura area) and other centers in the greater region.

fosa con relleno de carbón y cenizas, arrojó un resultado considerablemente más antiguo: 1755+/-37 años AP que, calibrado, da una fecha situada entre el 140- 390 DC. ${ }^{5}$ Teniendo en cuenta tanto las características y la potencia de ocupación de los recintos excavados, y los fechados de contextos funerarios cercanos como la longevidad de las especies vegetales de la región, el primer fechado parece ser el más preciso. ${ }^{6}$ 


\section{Sitio Pulac 050}

\section{Escaramayu}

Proyecto arqueológico Pulacayo

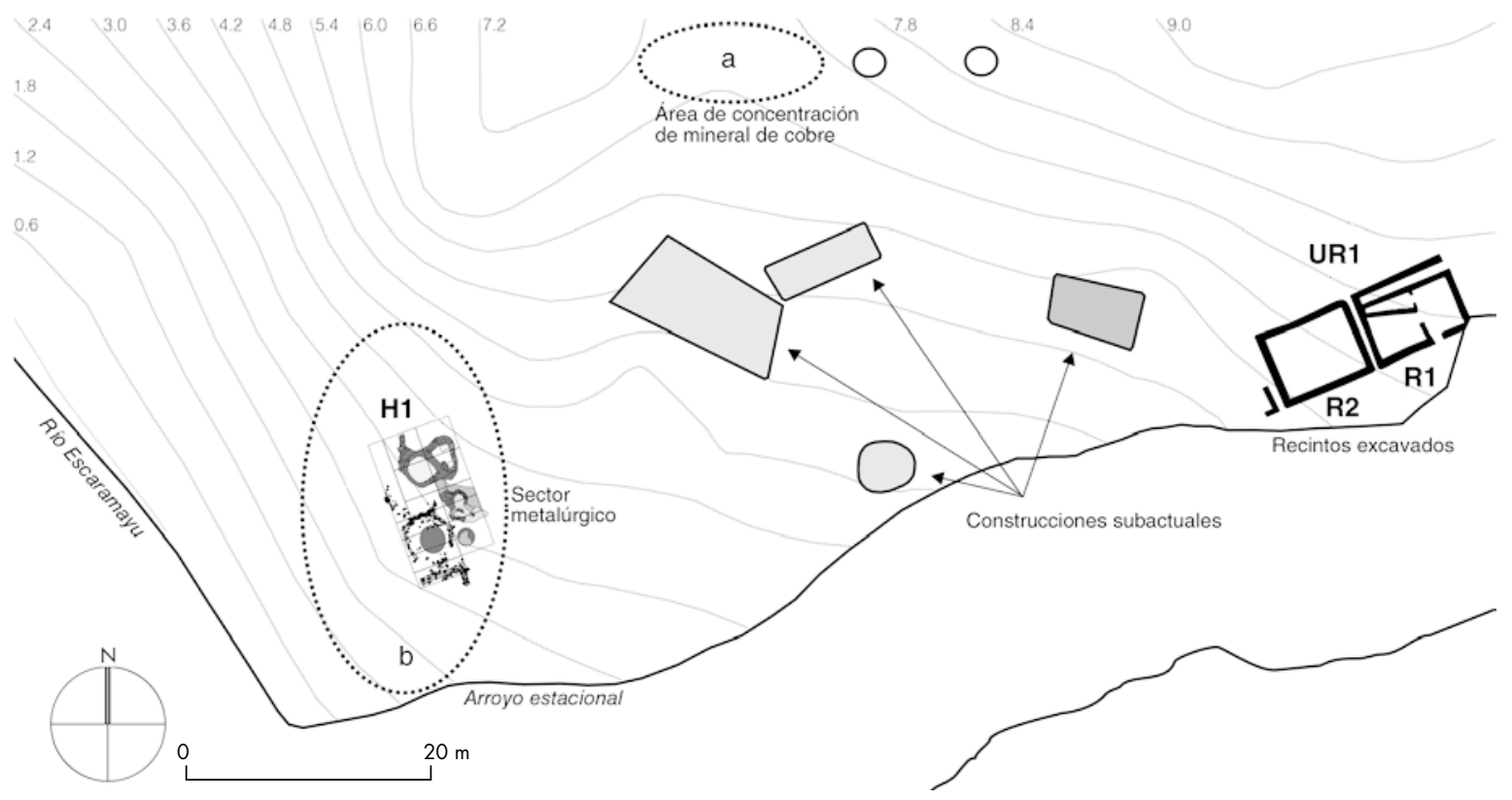

Figura 5. Plano del sitio Pulac 050 con localización de los sectores estudiados.

Figure 5. Pulac 050 site plan with location of the sectors studied.
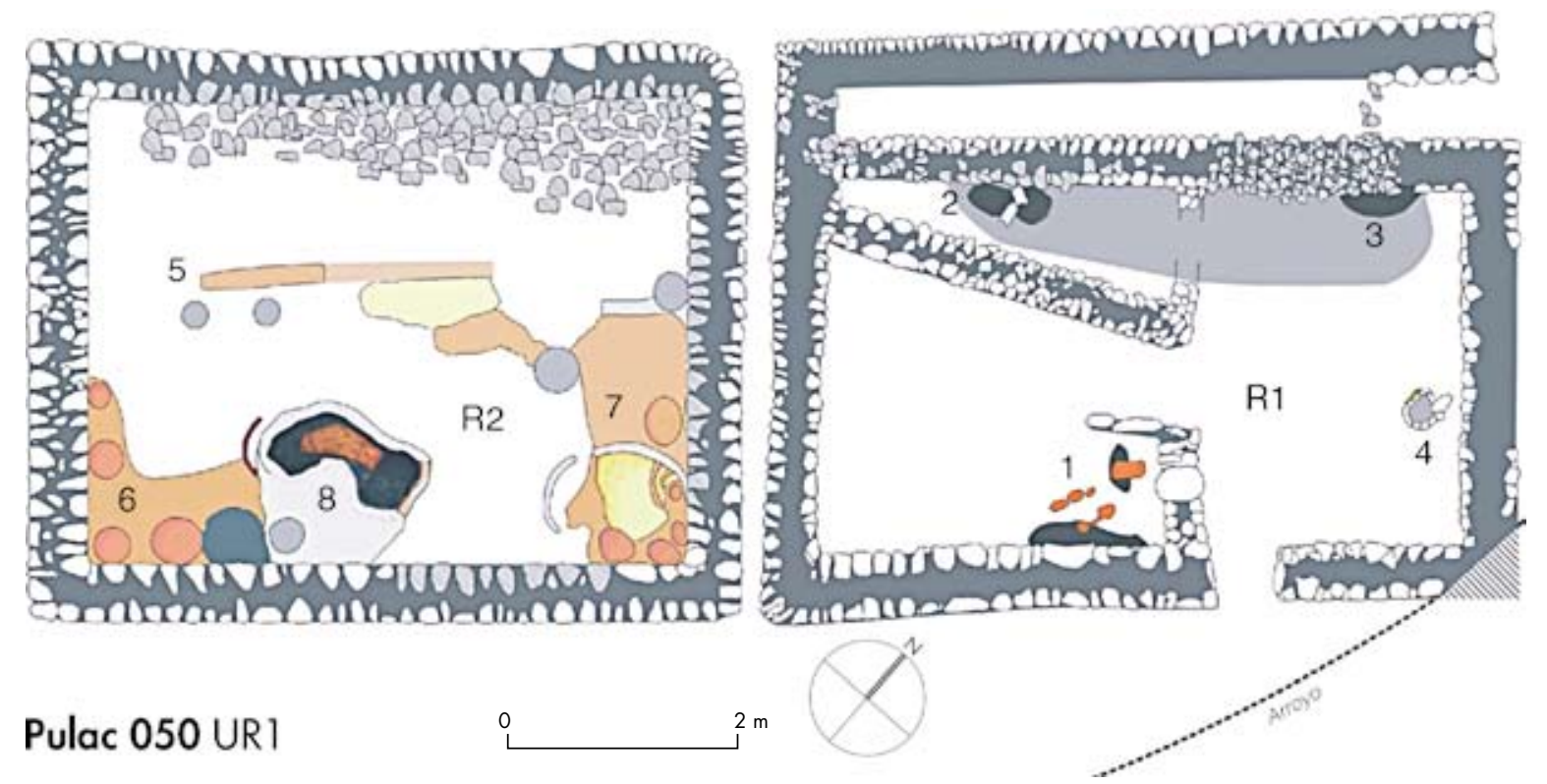

Pulac 050 UR 1

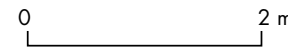

Figura 6. Recintos excavados en Pulac 050. 1, 2 y 3: estructuras de combustión (fogones); 4: depósito en
en arcilla; 6 y 7: banqueta en arcilla con piletas y pequeñas fosas; 8: estructura de combustión (horno).

Figure 6. Excavated enclosures at Pulac 050 site. 1, 2 \& 3: combustion structures (hearths); 4: stone deposit; 5: transverse clay bench; $6 \&$ 7: clay benches with sinks and small cavities; 8: combustion structure (furnace). 

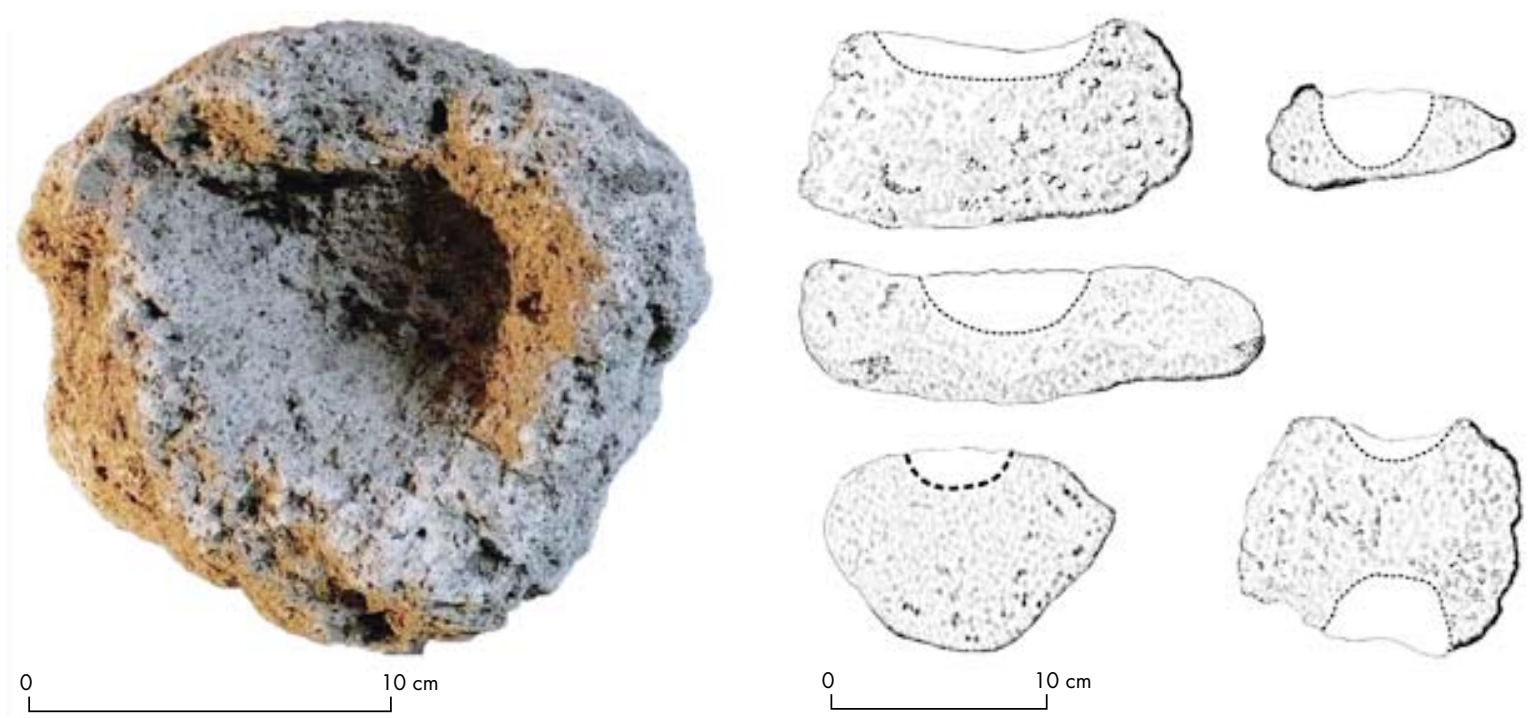

Figura 7. Dibujos y fotografía de los bloques formatizados de piedra pómez hallados en el sitio Pulac 050. Figure 7. Drawings and photograph of shaped pumice stone blocks found at the Pulac 050 site.

\section{El sector metalúrgico}

Por su parte, en el sector metalúrgico, cuya área se extiende aproximadamente sobre $500 \mathrm{~m}^{2}$ y delimita con el río Escaramayu, la distribución y densidad de materiales sobre la superficie señalan la existencia de dos áreas productivas continuas, pero a la vez diferenciadas: un área, sin estructuras, pero con abundantes materiales en superficie, como morteros y yunques (fig. 8), que sugieren que ésta estuvo destinada a la preparación del mineral para su posterior elaboración adicional, y otra, donde se realizaron actividades metalúrgicas como la fundición de menas metálicas y la refinación del metal obtenido. Sobre la superficie de ambas áreas se registraron abundantes fragmentos minerales de color verde. Muestras de estos minerales, tomadas en los dos sectores, fueron analizadas por difracción de rayos $\mathrm{X}$ determinando la presencia de una mezcla de óxidos (tenorita, cuprita), carbonatos (malaquita, azurita) y cloruros (atacamita) de cobre.

En el área metalúrgica se registraron por lo menos cuatro estructuras de combustión enterradas (fig. 9), fondos y paredes de hornos, abundantes bloques de piedra pómez y diversos útiles: manos, morteros, alisadores, semejantes a los hallados en los recintos excavados. Una gran densidad de escorias vitrificadas (fig. 10) de formas diferentes, productos de hornos de extracción, cubre la superficie de la zona. Escorias delgadas y del tipo plano (plate slag), semejantes a la muestra de Pulac 050 ilustrada en la figura 10, fueron registradas igualmente en sitios arqueológicos de la Edad de Bronce en Anatolia y en Austria (Bachmann
1982). Estas escorias son subproductos resultantes de la fundición de menas de sulfuros de cobre.

Varios de estos materiales fueron analizados por el método de isótopo de plomo: muestras de menas metálicas extraídas de la mina actual de Pulacayo, mineral de cobre y gotas de cobre hallados en la superficie del sector metalúrgico del sitio, una muestra de mata de horno (sulfuro de cobre) -un subproducto de la fundición de menas- y una muestra sacada del brazal de bronce estannífero procedente de la cueva de Pulacayo. Los resultados de estos análisis (Gráfico 1) muestran, por un lado, una coincidencia muy estrecha entre las firmas isotópicas características de las menas metálicas de la mina actual de Pulacayo y, por otro, las firmas isotópicas del mineral de cobre, de las gotas de cobre y de la mata de horno halladas en el sitio Pulac 050. Es evidente que el mineral de cobre de Pulac 050 provino del depósito mineralógico de Pulacayo, y las gotas de cobre representan los productos de la fundición del mineral de cobre explotado del depósito geológico de Pulacayo. Todos los datos isotópicos de plomo sugieren, fuertemente, que el depósito de mineral metálico de Pulacayo fue explotado por los pobladores de Pulac 050 durante el Horizonte Medio y que este mismo mineral fue fundido en el sitio Pulac 050. De esta manera, la firma isotópica de plomo del brazal de la cueva de Pulacayo está incluida en la estrecha agrupación de análisis en el diagrama formado por los otros materiales analizados. Sin embargo, esto no quiere decir que el brazal haya sido fabricado en el sitio Pulac 050. No obstante, los análisis indican que el cobre utilizado para fabricar 


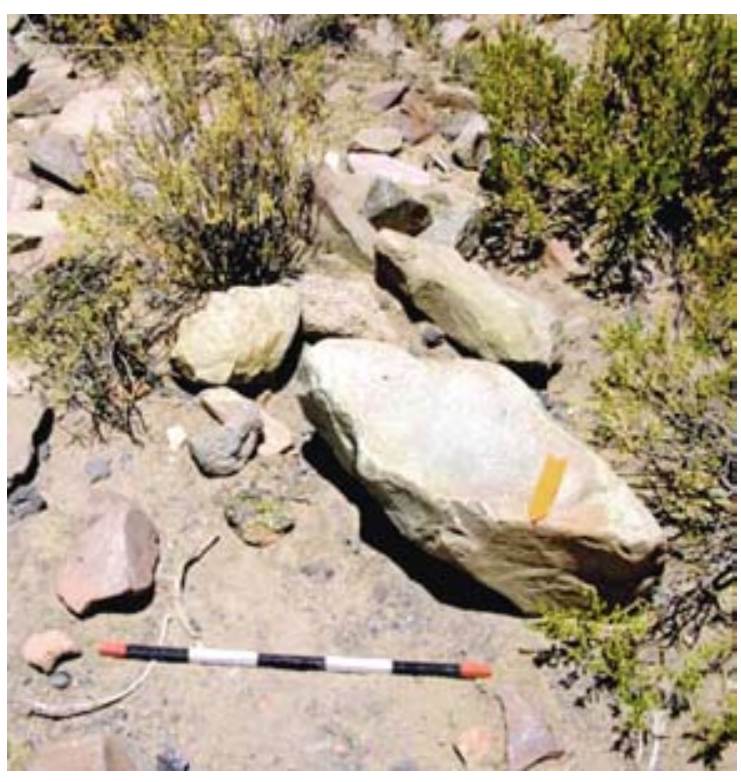

Figura 8. Fotografía de un yunque lítico hallado en cercanía de los hornos del sector metalúrgico de Pulac 050.

Figure 8. Photograph of a grinding stone found near the furnaces in the smelting sector of Pulac 050. el brazal fue fundido igualmente a partir de menas extraídas de la antigua mina de Pulacayo.

\section{El horno $\mathrm{H}-1$}

Dentro del área metalúrgica del sitio Pulac 050, muy cerca del margen este del río Escaramayu, se encuentra un horno de grandes dimensiones (horno H-1 en la fig. 9) que fue parcialmente destruido en los años 1960 por un pastor que vivía en el mismo sitio. Como consecuencia, la parte superior de la estructura ha sido destruida, impidiendo su registro, así también como la superestructura. Afortunadamente, tratándose de una estructura semisubterránea, el horno sólo fue destruido en su parte superior, permitiendo de esta manera que las excavaciones exhumaran rasgos importantes de la arquitectura interna y externa del mismo. Sin embargo, al encontrarse tanto la cámara propia del horno como el área para cargar combustible colmatadas de sedimento de relleno postocupacional, se decidió, por precaución, no fechar el abundante carbón hallado en el fondo.

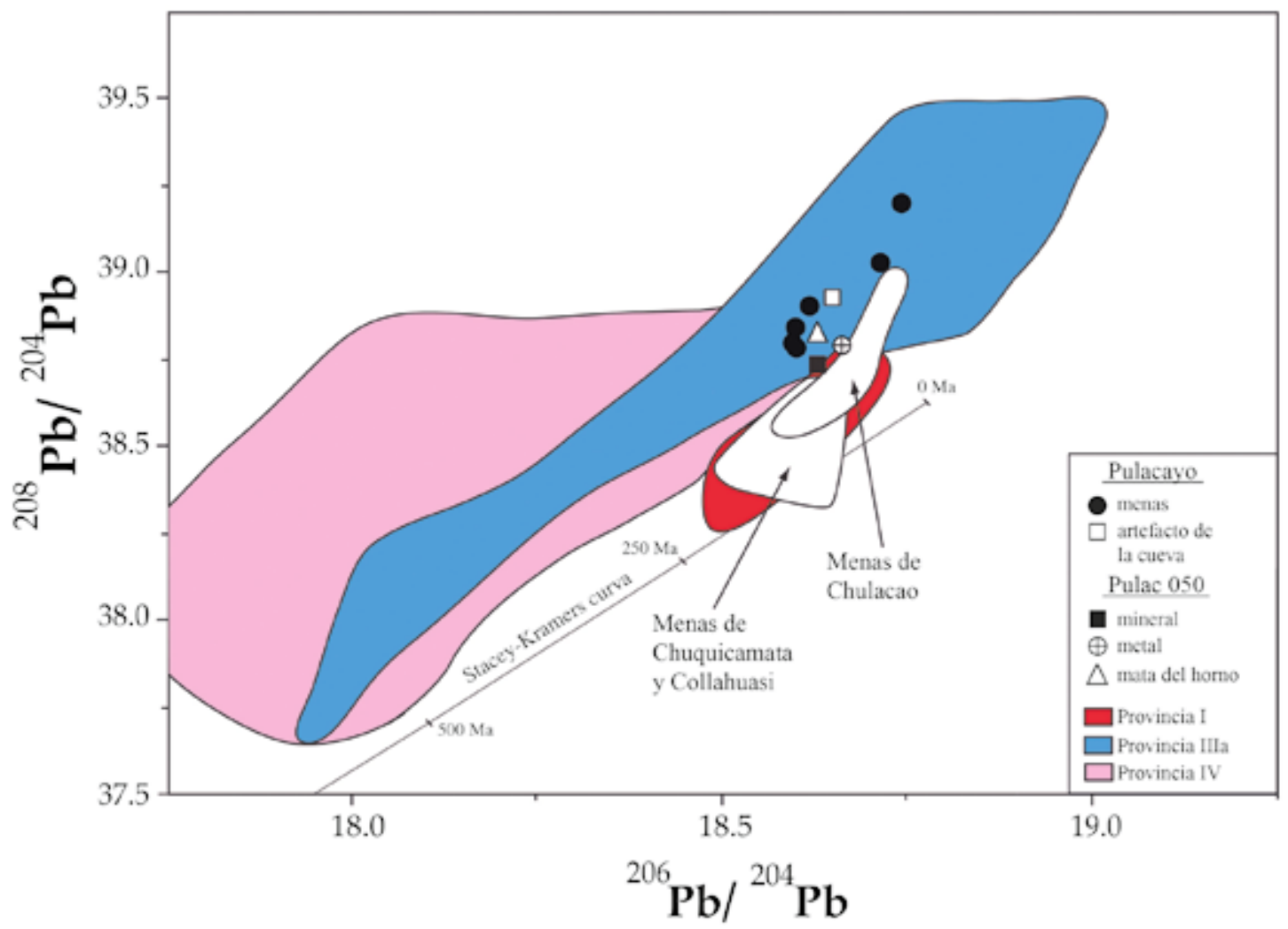

Gráfico 1. Gráfico con los valores de los cocientes de los isótopos de plomo (Pb) determinados para: menas de la mina de Pulacayo; muestras de mineral de cobre, gotas de cobre y mata (producido durante la fundición de menas de sulfuros de cobre) encontradas en el sitio Pulac 050; y una muestra de metal del "brazal" estañífero de la "Cueva de Pulacayo".

Graph 1. Graph depicting the lead (Pb) isotope ratios determined for: ore from the Pulacayo mine; specimens of copper mineral, droplets of copper and matte (produced during the smelting of copper sulfide ore) found at the Pulac 050 site, and a sample of metal from the tin bronze "arm band" found at the "Cueva de Pulacayo." 


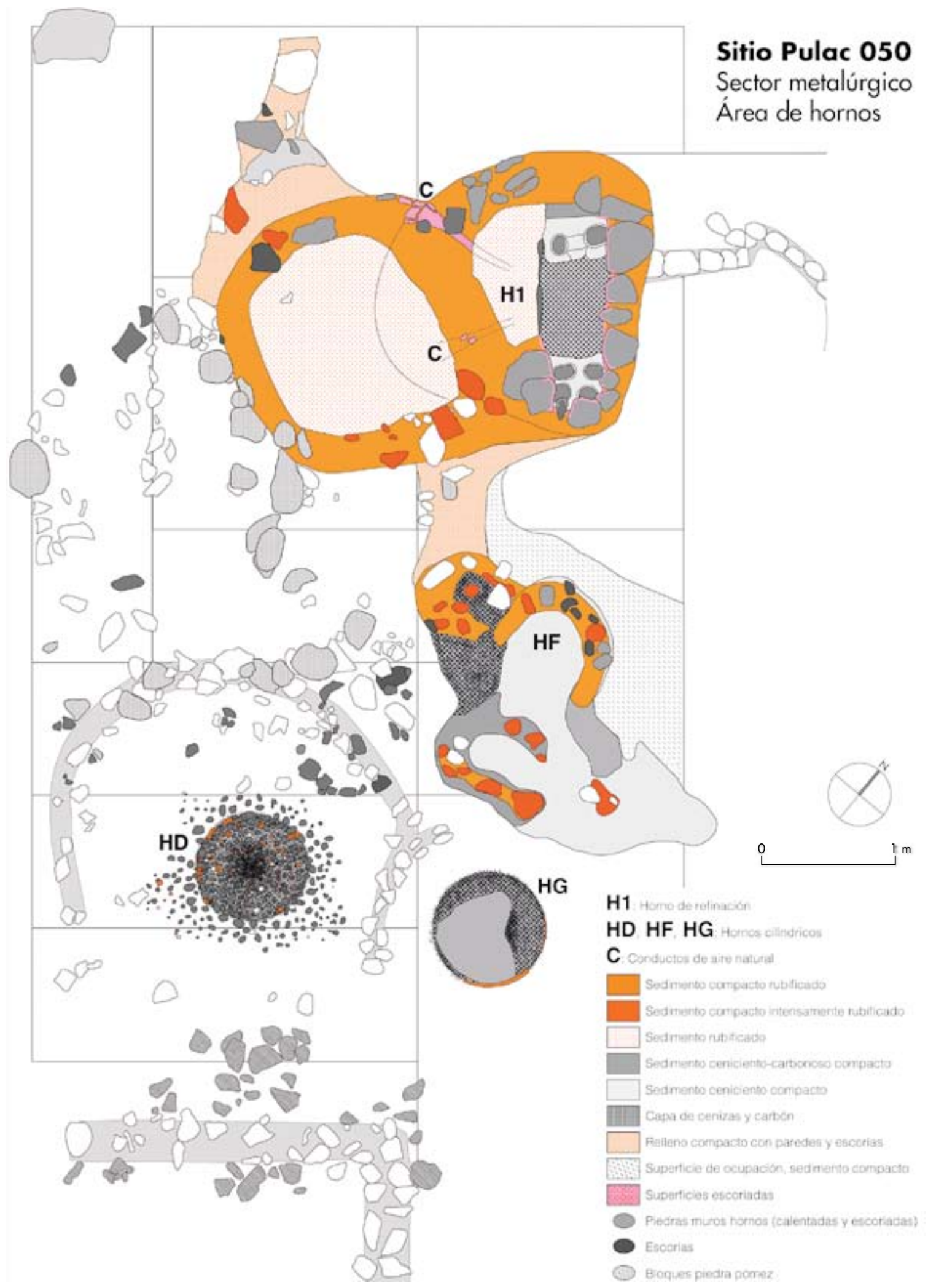



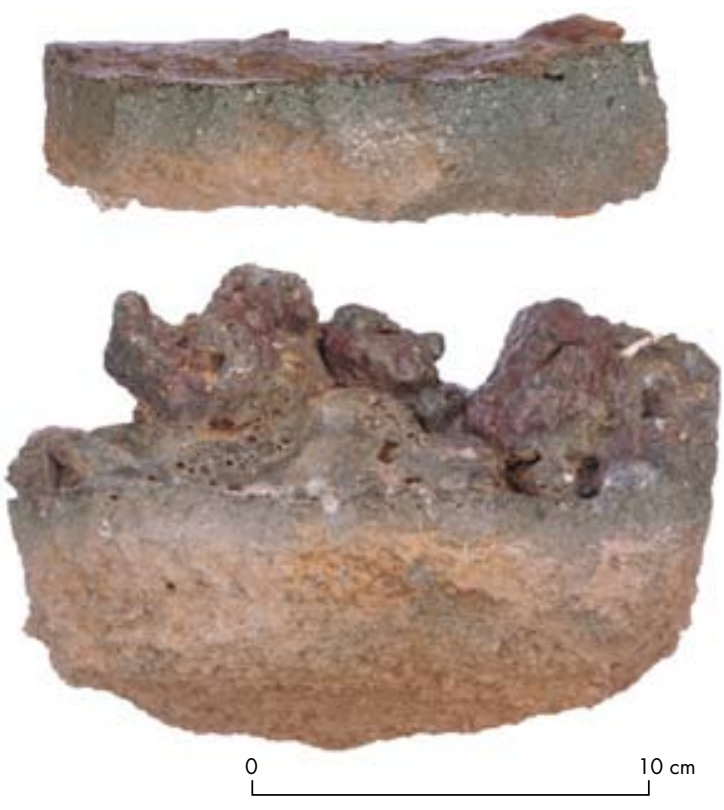

Figura 10. Variedades de escorias metalúrgicas encontradas en la superficie del sector de los hornos. La forma de escoria plana (arriba) ha sido registrada como un subproducto de la fundición de menas de sulfuros de cobre en sitios arqueológicos en Anatolia y Austria fechados para la Edad de Bronce.

Figure 10. Varieties of metallurgical slag found on the surface of the furnace sector. The flat, plate slag (shown above) has been identified as a byproduct of copper sulfide smelting at archeological sites in Anatolia and Austria and dated to the Bronze Age.

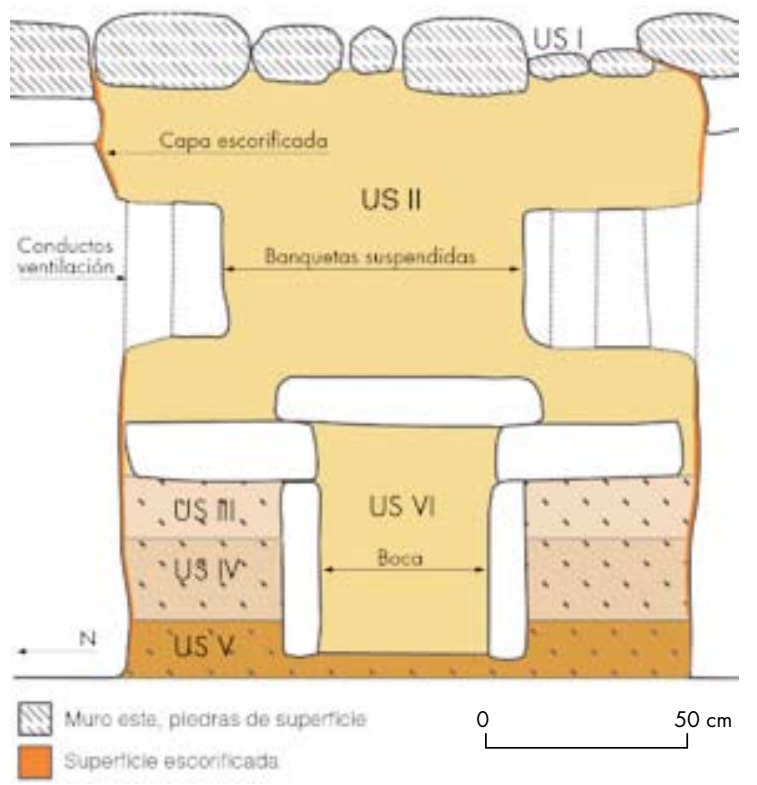

Figura 11. Perfil del muro este (cara oeste) de la cámara del horno $\mathrm{H}-1$.

Figure 11. Cross-section of the east wall (western face) of the chamber of furnace $H-1$.
Las paredes del horno, vitrificadas en su superficie interior (figs. 9, 11), están construidas con piedra y argamasa de tierra o arcilla. El horno se distingue por su gran tamaño y complejidad -la cámara mide entre 1 y 1,4 m- y cuenta con un conjunto único de dos banquetas construidas de tierra, suspendidas dentro de la cámara: una de la pared norte y la otra de la pared al sur (figs. 9, 11, 12). La banqueta del norte se encuentra perforada con dos canales que corren por completo a través de su altura, mientras que la banqueta sur contiene cuatro de estos canales. El diámetro de cada canal es de entre 10 y $15 \mathrm{~cm}$, aproximadamente.

Describimos la arquitectura del horno con sus banquetas y canales para conducir el aire caliente con el término 'único', porque no conocemos evidencias de este tipo de estructura de horno ni en las publicaciones arqueológicas sobre los Andes prehispánicos ni en la literatura de la Colonia. ${ }^{7}$ La alimentación en combustible debió ser realizada alternadamente desde la parte inferior (precalentamiento, limpieza de cenizas) (fig. 11) y, probablemente, por encima de un techo (fig. 13b) que sugerimos pudo haber sido parte de la

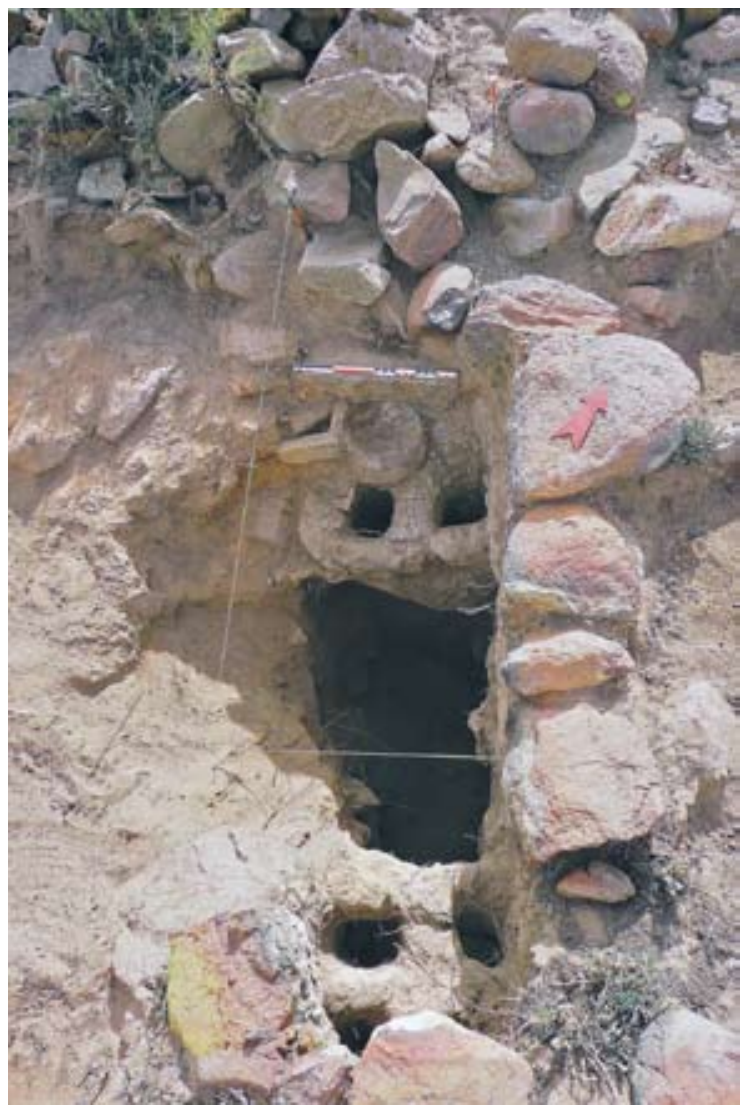

Figura 12. Fotografía de la cámara del horno H-1, mostrando las dos banquetas y sus conductos para el aire caliente.

Figure 12. Photograph of furnace $H-1$ chamber, showing the two benches and hot air vents. 
superestructura. Una muestra de carbón hallada en los niveles inferiores al interior del horno fue analizada e identificada como tola (Parastrephia lepidophylla), un arbusto de puna que crece abundantemente en los alrededores del sitio. ${ }^{8}$

Por lo menos, dos conductos de ventilación natural, direccionados desde el exterior de la pared este al centro de la cámara del horno, y ubicados a la misma altura de las banquetas suspendidas (figs. 9, 13a, 13b), permitieron la generación de altas temperaturas. La presencia en contexto primario de un recipiente de cerámica por encima de la banqueta norte (fig. 14), al mismo nivel que los conductos de ventilación natural, señala que recipientes de este tipo fueron colocados por

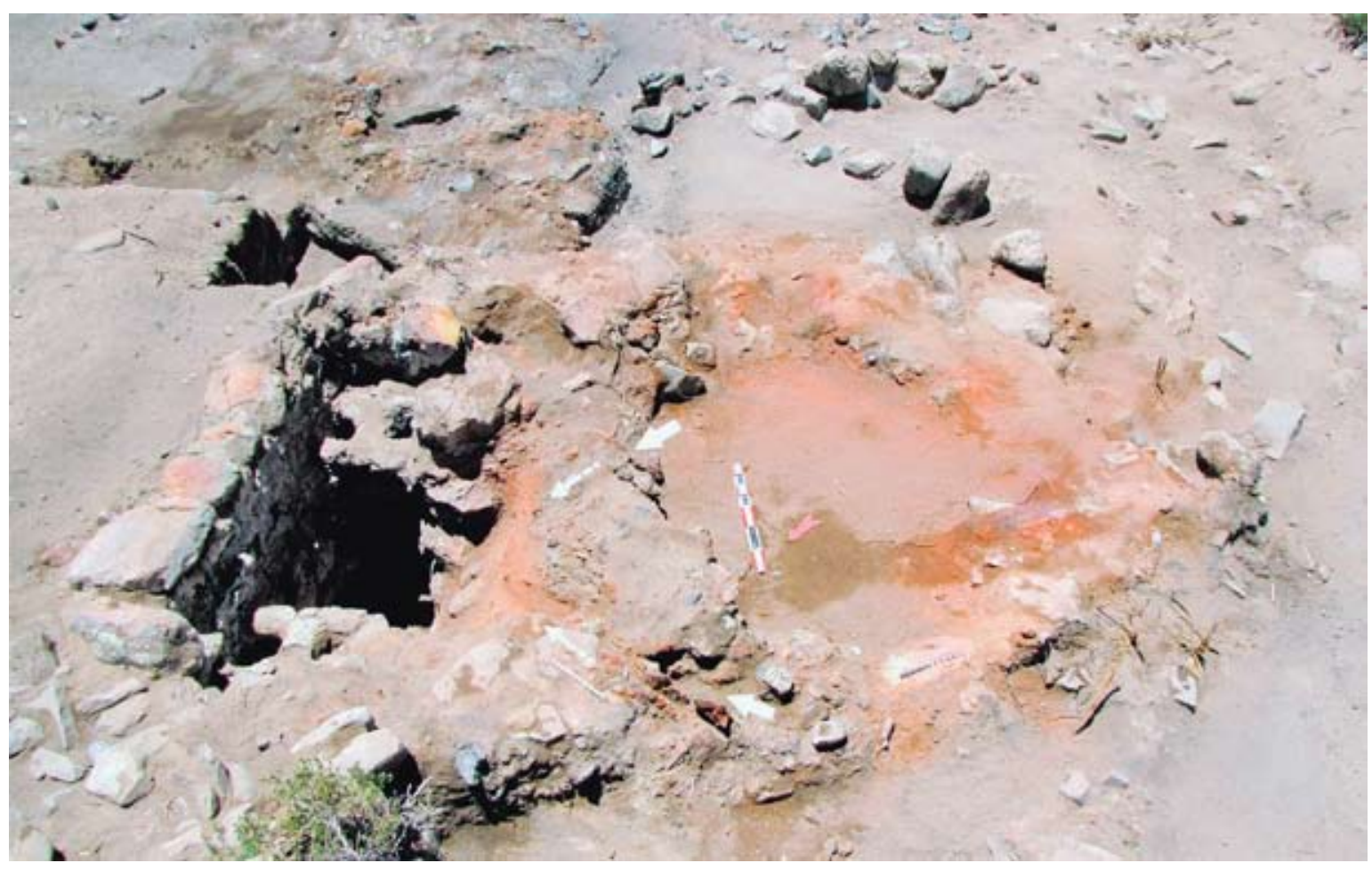

Figura 13a. Fotografía de la cámara del horno H-1 y las estructuras asociadas al oeste. Las flechas blancas indican la ubicación y orientación de los conductos de aire natural.

Figure 13a. Photograph of furnace H-1 chamber and associated structures on the west. The white arrows indicate the location and orientation of natural air vents.

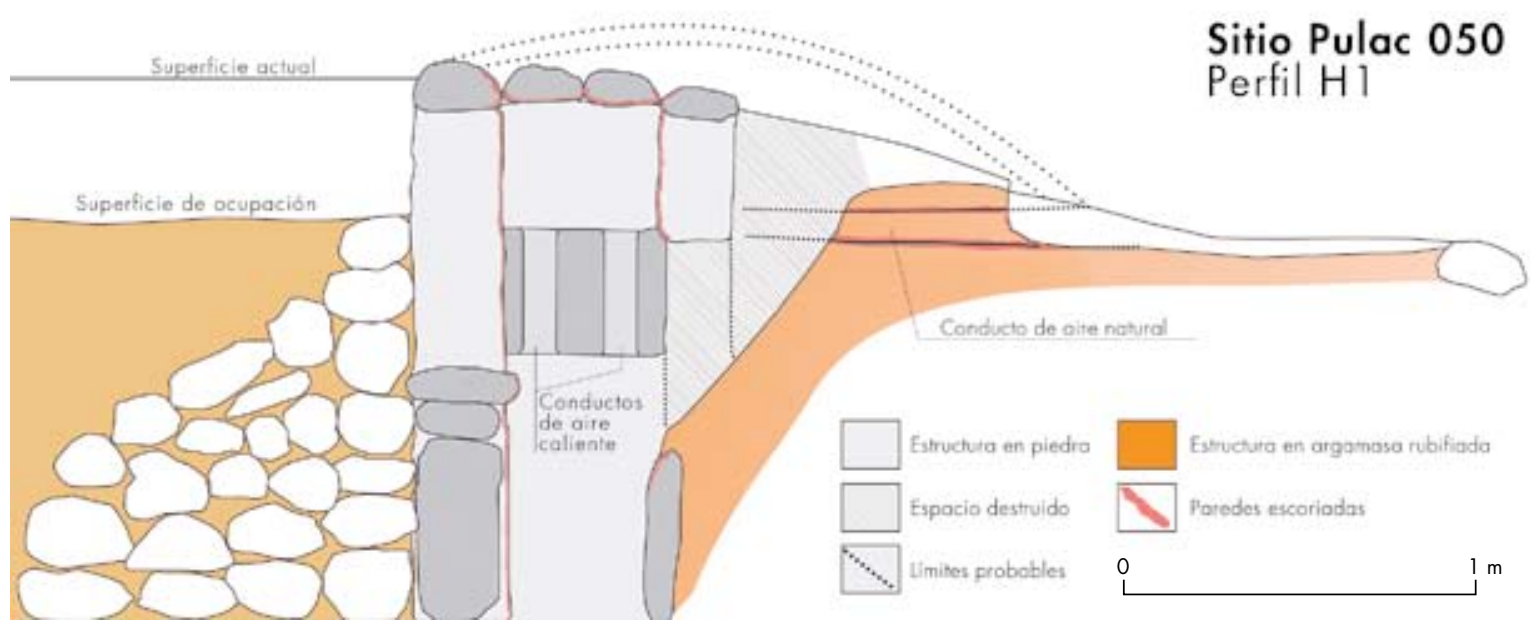

Figura 13b. Perfil del horno H-1 mostrado en la figura 13a.

Figure 13b. Cross-section of furnace H-1 shown in Figure 13 a. 

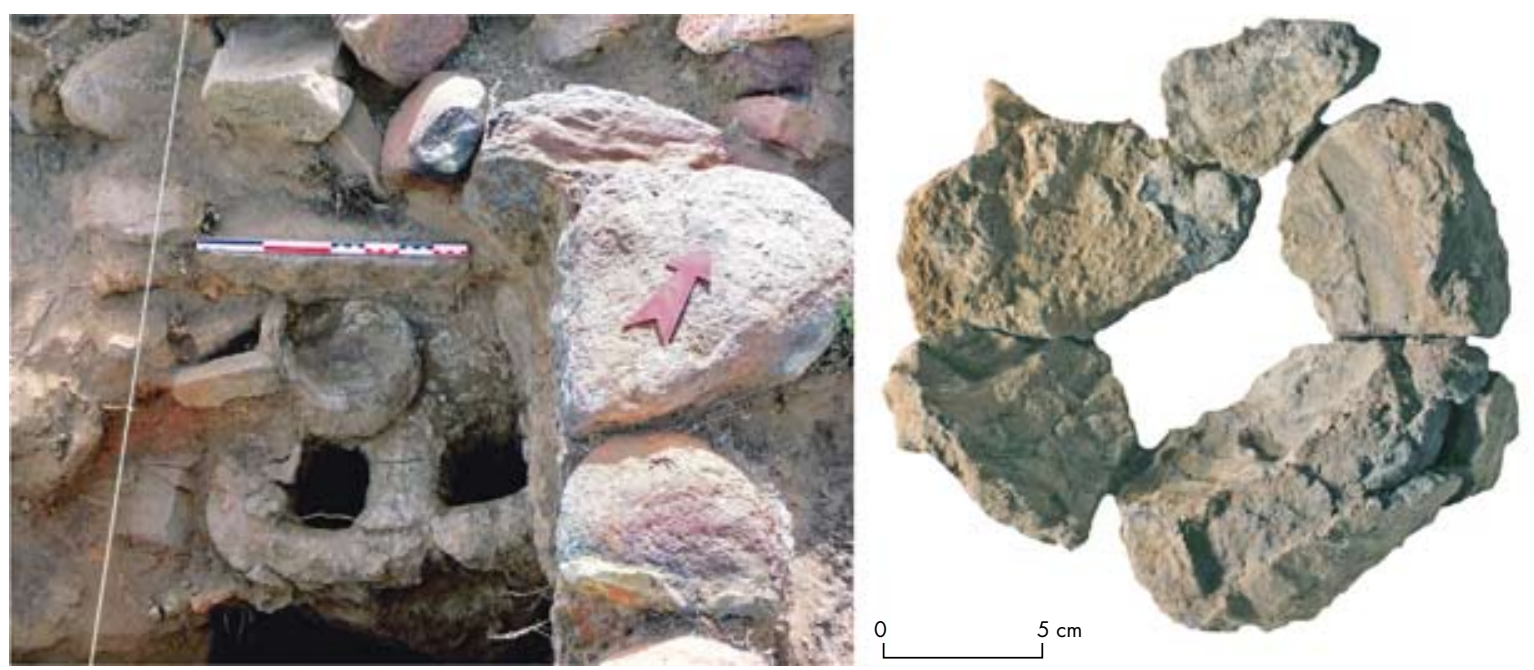

Figura 14. Recipiente hallado in situ sobre una de las banquetas suspendidas del horno H-1 y un detalle del mismo postexcavación. Figure 14. Vessel found in situ on one of the suspended benches of furnace H-1 and detail of the vessel, post-excavation.

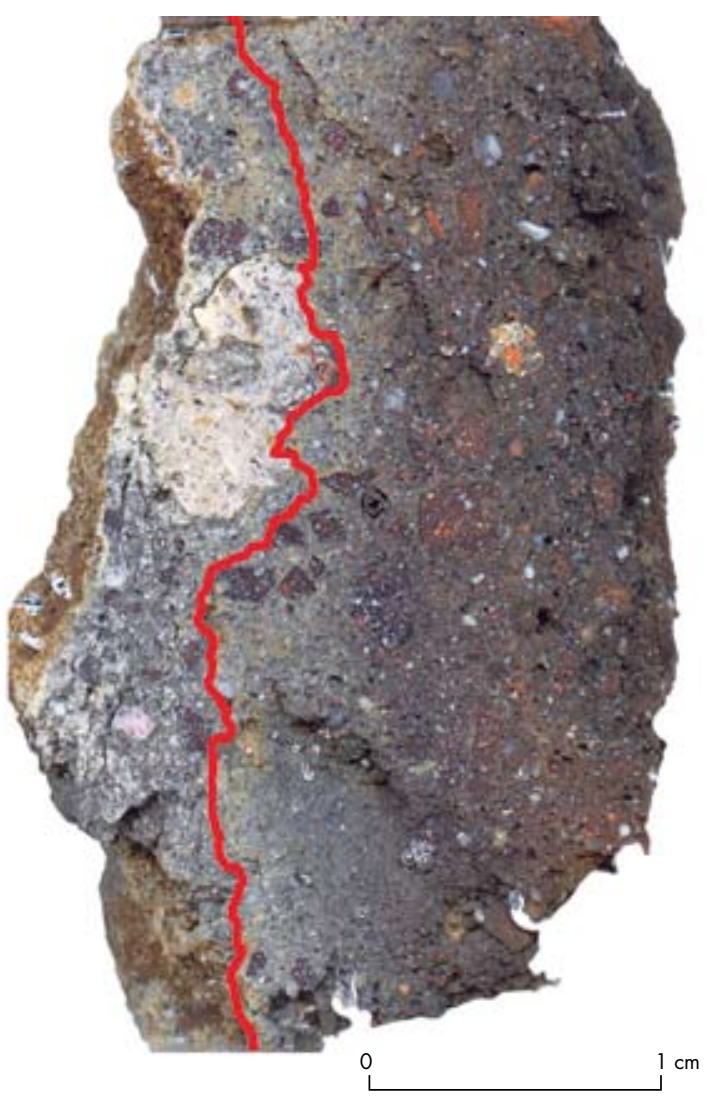

Figura 15. Corte transversal de una muestra tomada de la superficie interior de uno de los conductos de aire caliente de la banqueta norte del horno H-1. La superficie (a la izquierda de la línea roja) ha sido escorificada hasta una profundidad de $7 \mathrm{~mm}$.

Figure 15. Cross-section of a sample from the interior wall of a hot air vent on the north bench of furnace $H-1$. The vent wall surface (to the left of the red line) has been vitrified to a depth of $7 \mathrm{~mm}$. encima de las aberturas de los canales, posiblemente para contener y calentar al mismo tiempo otros recipientes más pequeños del tipo crisol.

Aunque la superficie del sitio Pulac 050 está cubierta por pequeños fragmentos de mineral de cobre, y a pesar de que el área para almacenar y cargar combustible contenía rellenos ricos en este mineral, todavía no hay evidencia directa o decisiva sobre la o las funciones específicas de este horno. Actualmente sólo se puede afirmar que se trataba de un horno de refinación, con banquetas suspendidas y sistema de ventilación natural, probablemente asociado con el uso de crisoles.

\section{Temperaturas alcanzadas dentro y encima de los canales de banquetas}

En un intento por aclarar estas preguntas fundamentales decidimos investigar, primero, dos características del funcionamiento del horno $\mathrm{H}-1$ : la temperatura alcanzada en las superficies interiores de los canales de las banquetas y la temperatura alcanzada en la superficie interior del recipiente, y la morfología y composición de tales superficies. En la figura 15 vemos un corte transversal de una muestra de la superficie interior de un canal. La línea roja traza el borde entre la superficie vitrificada de la pared del canal, a la izquierda, y la cerámica de abajo que no está alterada. La temperatura alcanzada dentro del canal fue suficientemente alta como para vitrificar la superficie de la pared interior hasta una profundidad de $7 \mathrm{~mm}$. Un programa de computadora llamado ThermoCalc (Kaufman 2001) permitió determinar la temperatura del comienzo de la vitrificación de la pared del canal. El programa calcula la temperatura en 
la que la vitrificación de un material cerámico comienza a producirse, así como la temperatura en que el material se derrite completamente. ${ }^{9}$

Después de haber determinado la composición química de las muestras sacadas de la pared interior del canal, se ingresaron los datos en el programa ThermoCalc. Se cargaron los valores de composición solamente para los óxidos mayores de los elementos determinados en las muestras. Los resultados de los cálculos se presentan en forma de curvas que grafican la fracción de las fases (p. e.: sólido, sólido + líquido o líquido) presentes en el material, en función de la temperatura.

El esquema producido por ThermoCalc, mostrado en el Gráfico 2, indica que la temperatura del comienzo de la vitrificación de la pared interior del canal fue de $1128^{\circ} \mathrm{C}$. Aun así, es probable que el horno funcionara a temperaturas más altas. El examen de la microestructura de la superficie vitrificada por la técnica de microanálisis electrónico reveló la presencia de inclusiones metálicas minúsculas atrapadas en la capa vitrificada, que fueron transportadas allí por medio de los gases calientes y ascendentes. Estas inclusiones fueron identificadas como plomo.

\section{Temperatura alcanzada dentro del recipiente}

La figura 16a muestra un detalle de la superficie interior de un fragmento del recipiente hallado en el horno; este exhibe una zona gruesa de color negra, fuertemente

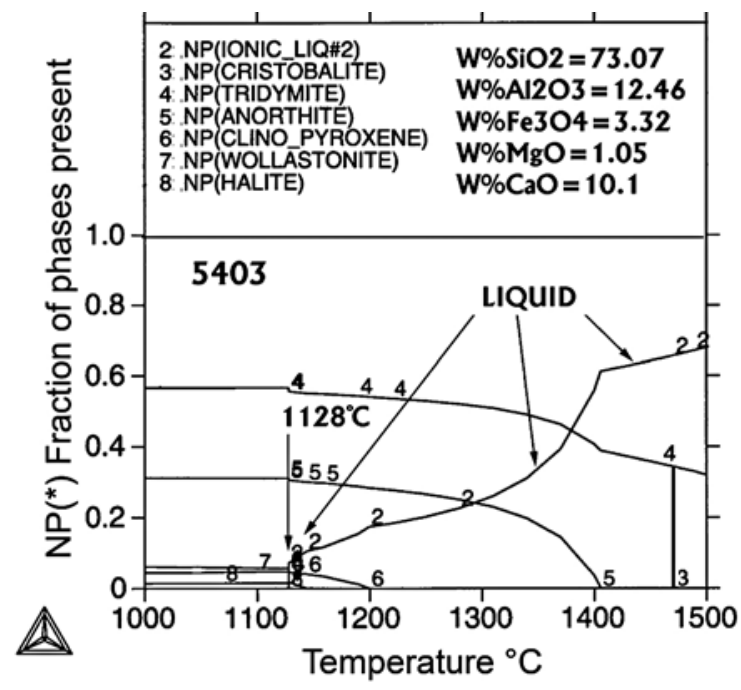

Gráfico 2. Gráfico producido por el programa ThermoCalc que indica la temperatura $\left(1128^{\circ} \mathrm{C}\right)$ alcanzada dentro del conducto de aire caliente al comienzo de la vitrificación de la superficie de la pared.

Graph 2. Graph generated by the ThermoCalc program, indicating the temperature reached $\left(1128^{\circ} \mathrm{C}\right)$ inside the bot air vent when vitrification began on the inside surface of the vent wall.

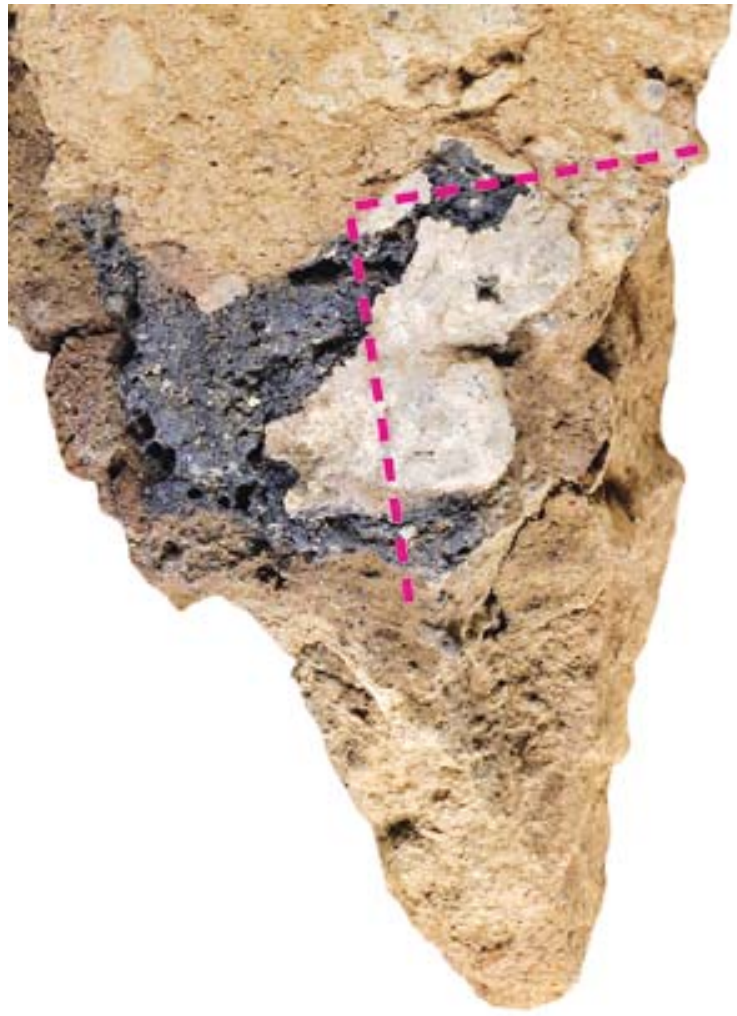

Figura 16a. Detalle de la superficie interna de un fragmento del recipiente hallado en depósito primario sobre de la banqueta norte del horno H-1. Se indicada la localización del corte transversal realizado, el cual toma la capa superficial, negra y vitrificada. Figure 16a. Detail of the interior surface of a fragment of the vessel found in the primary deposit on top of the north bench of furnace $H$-1. The location of the cross-section is shown by the dotted red line. The section includes the black, vitrified surface layer.

vitrificada. Con un corte transversal (fig. 16b), tomado precisamente en este punto (indicado en el fragmento), fue posible analizar el material que cubre la superficie interior del mismo. En el corte, la línea roja traza el borde entre la capa de material negro que cubre la superficie interior y la cerámica debajo de esta capa. La capa negra es un vidrio de silicato de plomo, rico en azufre, que contiene cristales de feldespato y algunas gotas de plomo metálico; se trata de una escoria de plomo.

En una fotomicrografía del mismo corte (fig. 17a) se observa el borde entre la escoria de plomo, por encima de la línea roja, y la superficie interior de la cerámica. Un análisis del corte con el MEB indica la forma en que el plomo (en rojo; fig. 17b) y el azufre (en amarillo; fig. 17c) están concentrados dentro de la escoria con un límite bien separado del cuerpo de la cerámica. Es importante, también, destacar que en la fotomicrografía del corte del recipiente mostrado en la figura 18a, la cerámica que aparece por debajo de la línea roja es 


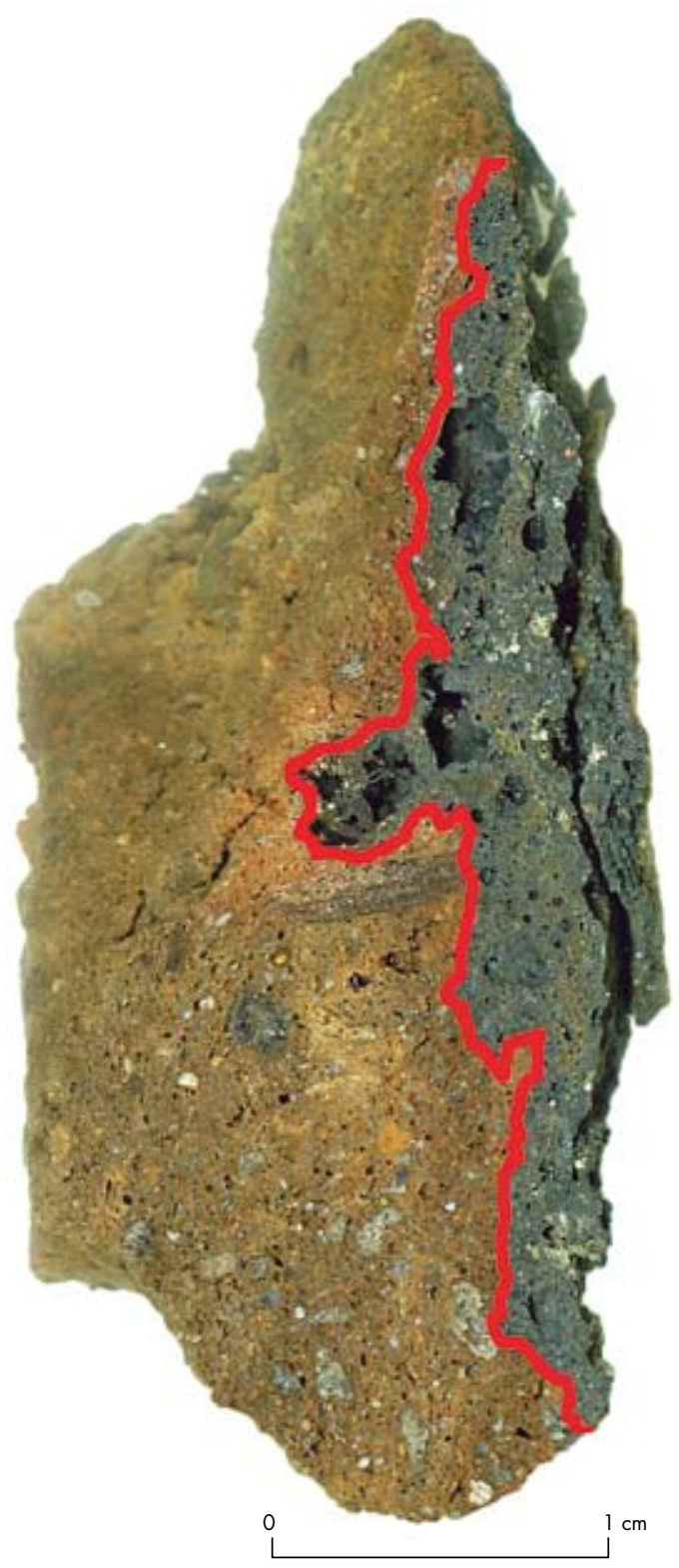

Figura 16b. Corte transversal del fragmento correspondiente a la figura 16a una vez pulido, revelando la capa negra y vitrificada que cubre la superficie interior del recipiente.

Figure 16b. Cross-section of the vessel fragment shown in Figure 16 a after polishing to reveal the black vitrified layer that covers the interior surface of the vessel.

gruesa y llena de poros grandes. La microestructura en la zona interfacial revela la ausencia de vitrificación de la cerámica. La escoria, en un estado líquido o semilíquido, infiltró los poros, solidificándose allí y alrededor de los granos de cerámica. En la figura 18b vemos una gota de plomo colgando de la pared de un poro dentro de la capa de escoria.
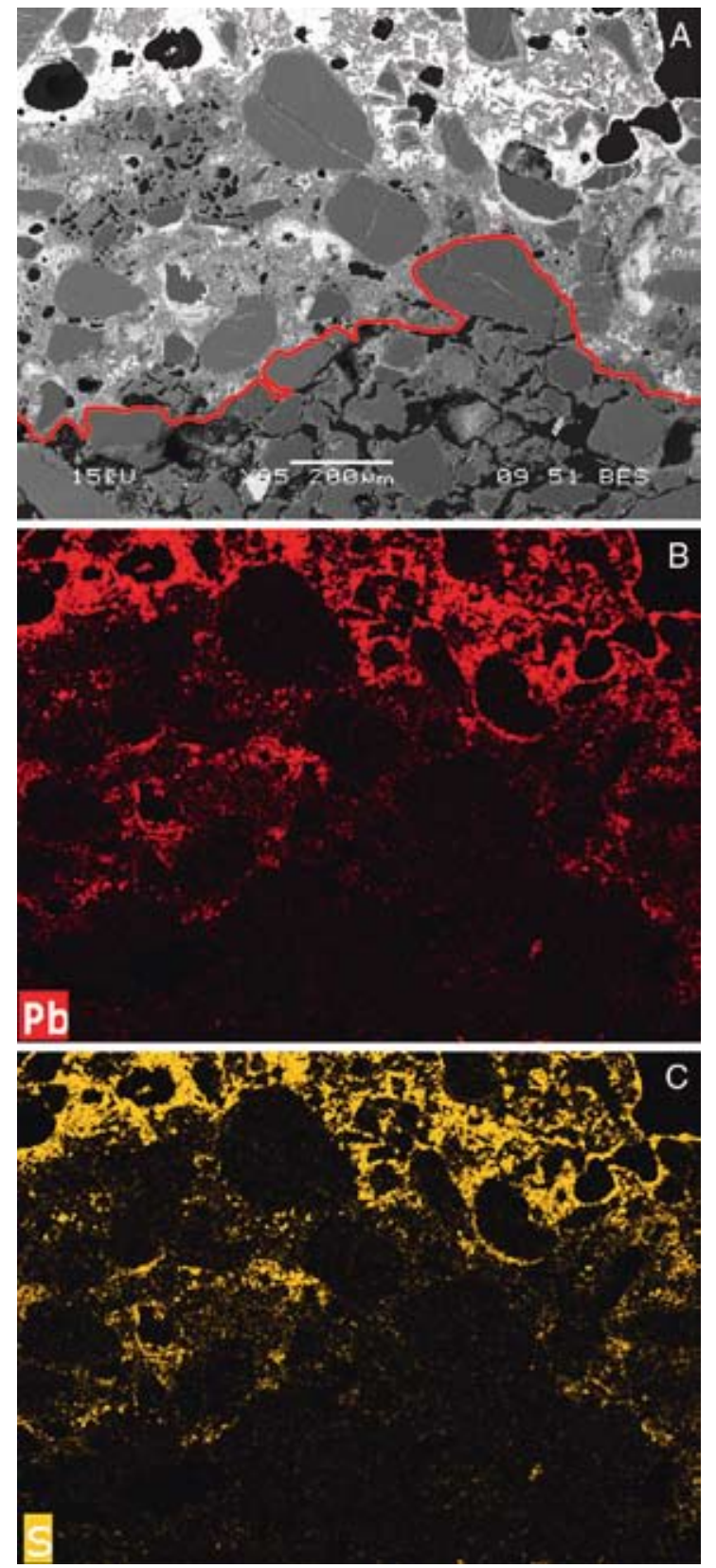

Figura 17. A) Fotomicrografía MEB del corte transversal pulido correspondiente a la figura 16b (aumento: 95). Se observa claramente el límite entre la escoria de plomo, ubicada por encima de la línea roja, y la superficie de la cerámica del recipiente. B) MEB mapa (en rojo) indica la ubicación del elemento plomo $(\mathrm{Pb})$ dentro de la escoria y su ausencia en el cuerpo de la cerámica. C) MEB mapa (en amarillo) indica la presencia del elemento azufre (S) dentro de la capa de escoria y su fuerte asociación con el plomo.

Figure 17. A) SEM photomicrograph of the polished cross-section corresponding to Figure $16 b$ (magnification: 95). The border between the lead slag, located above the red line, and the ceramic surface of the vessel, located below, can be seen clearly. B) SEM map (in red) indicating the location of lead ( $\mathrm{Pb}$ ) within the slag and its absence in the body of the ceramic. C) SEM map (in yellow) indicating the presence of sulfur $(S)$ inside the slag layer and its close association with lead. 


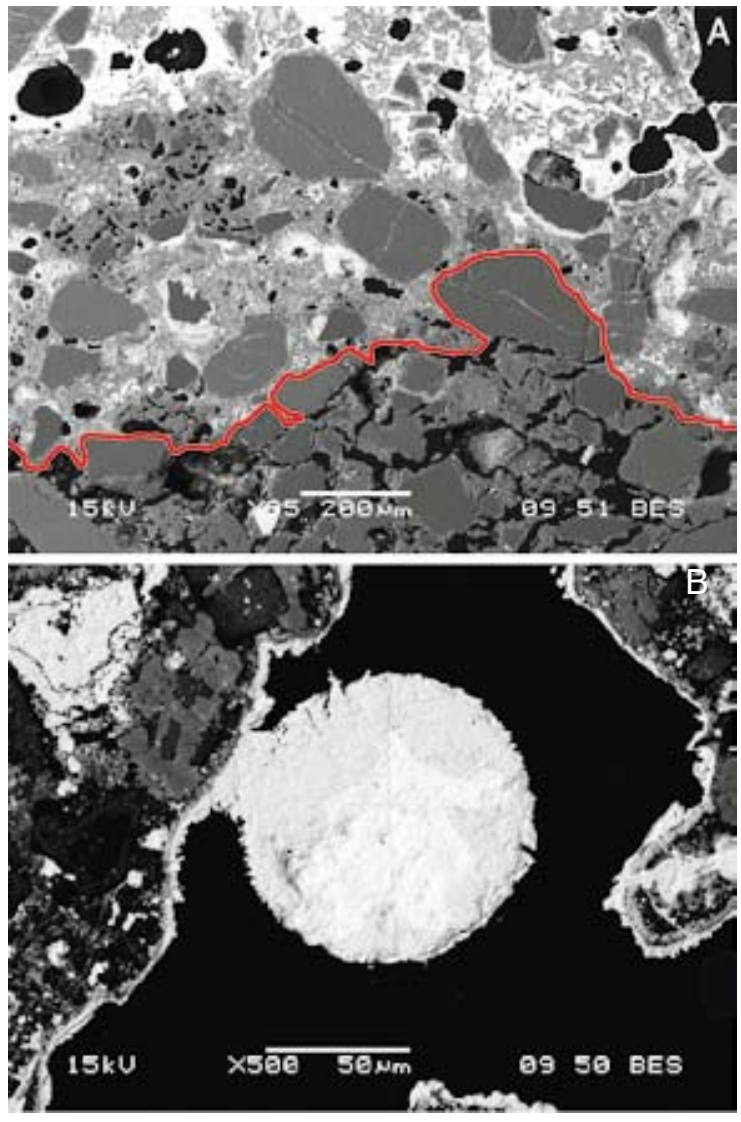

Figura 18. A) Ampliación de la fotomicrografía del MEB mostrada en la figura 17a. B) Fotomicrografía tomada con el MEB de una gota de plomo colgando de la pared de un poro dentro de la capa de escoria de plomo (aumento: 500).

Figure 18. A) Enlargement of the SEM photomicrograph shown in Figure 17 a. B) SEM photomicrograph of a drop of lead hanging from the wall of a pore within the lead slag layer (magnification: 500).

Cualquier procesamiento que hubiese tomado lugar dentro del recipiente involucró una temperatura por debajo de la temperatura de vitrificación de la cerámica. El análisis por el programa ThermoCalc determinó la temperatura mínima para vitrificar la pared del recipiente: $1155^{\circ} \mathrm{C}$. Es importante mencionar el hecho de que no se haya detectado ninguna otra huella de metal -ni de plata, ni de cobre- atrapado en la pared del canal de la banqueta ni en la superficie interior del recipiente. La estrecha asociación entre el plomo y el azufre en la capa de escoria dentro del recipiente sugiere que el procesamiento que tomó lugar dentro del horno incluyó, de una u otra forma, plomo o galena, el sulfuro de plomo. Numerosas fuentes históricas señalan que los metalurgistas andinos usaron la galena -soroche o surúchec- para fundir la plata de sus menas, por lo menos al final del Horizonte Tardío, antes de la invasión de los españoles. ${ }^{10}$ Por otro lado, también es posible que el plomo fuera usado en el horno $\mathrm{H}-1$ de Pulac 050 como parte de un proceso de refinación de un cobre impuro, ya fundido de sus menas. Si bien los datos son aún incipientes, sabemos que se trata de un horno de refinación, el cual generó temperaturas suficientemente altas para derretir el cobre, para fundir menas de cobre y para vitrificar menas de plomo.

\section{ESCORIAS, FUNDICIÓN Y REFINACIÓN}

Es importante señalar que el horno descrito se encuentra asociado, a escasos metros, con los restos de al menos otras tres estructuras de combustión (fig. 9), conformando un conjunto metalúrgico dentro de un espacio específico y parcialmente delimitado por muros de piedra. Los restos de estas otras tres estructuras muestran que se trataba de hornos cilíndricos o columnarios, con un diámetro aproximado de entre 0,9 y $1 \mathrm{~m}$, muy probablemente destinado a la fundición extractiva. Algunos pocos fragmentos de paredes de estos hornos hallados sobre la superficie muestran aperturas circulares, de alrededor de $10 \mathrm{~cm}$ de diámetro, aspecto que rememora los hornos de viento indígenas o buayrachinas (Van Buren \& Mills 2005; Téreygeol \& Cruz 2010) comunes en la región. Asimismo, es posible que la gran cantidad de restos de coladas de escoria de reducción, dispersa sobre toda la superficie del sitio, haya sido originada por estos hornos.

No se han examinado todavía los grandes fragmentos de escoria que se encuentran esparcidos sobre la superficie del sector metalúrgico, especialmente en el área delimitada por los tres hornos cilíndricos. Sin embargo, unos pequeños especímenes de material cristalino obtenidos en el mismo sector proporcionaron informaciones pertinentes sobre el posible funcionamiento de los hornos. Entre ellos, fueron hallados dentro del relleno del horno $\mathrm{H}-1$ restos de subproductos del procesamiento de menas metálicas (figs. 19 y 20). Dado que el horno H-1 fue bastante alterado después de su uso, y destruido parcialmente muy probablemente en la década del sesenta, y, dada la cercanía de los tres hornos cilíndricos al horno $\mathrm{H}-1$, no podemos asegurar con exactitud la procedencia de estos especímenes.

La figura 19 muestra un pequeño pan de forma ovalada cuya superficie se encuentra cubierta por una delgada capa de color negro. Un corte transversal, tomado a lo largo del eje indicado en la foto, posteriormente pulido, se muestra en la misma figura, por debajo del pan. El corte exhibe varios estratos de material de colores diferentes. La composición de los estratos mayores fue determinada por microanálisis electrónico. 


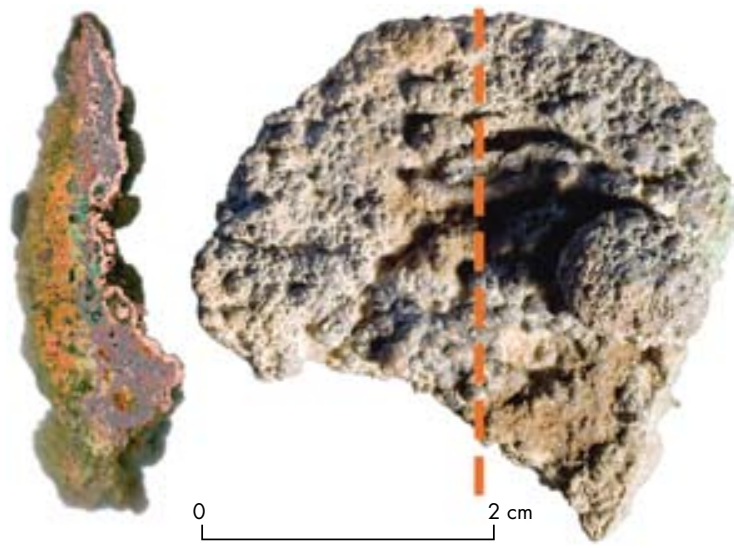

Figura 19. Muestra del pan de escoria cristalina hallada en el horno H-1. Un corte transversal, tomado a lo largo del eje indicado y pulido, se muestra por debajo del pan.

Figure 19. Sample of crystalline slag cake found in furnace H-1. As-polished cross-section taken along the dotted line is shown below the cake.

La capa negra y delgada de la superficie no es homogénea; ella se compone de una mezcla de óxido de plomo $\left(\mathrm{PbO}_{2}\right)$ y sulfuro de plomo $(\mathrm{PbS})$. Inmediatamente por debajo de esta capa superficial se encuentra otra capa delgada de cuprita $\left(\mathrm{Cu}_{2} \mathrm{O}\right)$. Ambas capas delgadas de $\mathrm{PbO}_{2}$ y $\mathrm{Cu}_{2} \mathrm{O}$ son, muy probablemente, el resultado de la corrosión de la superficie del pan durante su deposición ante los agentes ambientales. La cuprita se sobrepone a un estrato mucho más grueso de cobre metálico, que aparece de color rojo-rosado en el corte transversal (fig. 19). Se trata de una aleación de cobre y plata cuya concentración de plata no excede un promedio de $6,9 \mathrm{wt} \%$ (porcentaje por peso). Dentro de esta zona rica en cobre hay pequeños glóbulos de oxígeno de plomo $\left(\mathrm{PbO}_{2}\right)$ con una baja concentración de sulfuro, y también glóbulos de plata, algunos de los cuales son aleaciones que contienen $90 \mathrm{wt} \% \mathrm{Ag}, 5 \mathrm{wt} \%$ $\mathrm{Cu}$ y $4 \mathrm{wt} \% \mathrm{~Pb}^{11}$

El material que constituye la matriz del pan -el estrato ancho y de color gris-acero en el corte (fig. 19), ubicado debajo del estrato de cobre- se compone de sulfuro de cobre (calcocita: $\mathrm{Cu}_{2} \mathrm{~S}$ ). Unos glóbulos presentes dentro de la matriz, a veces situados en el borde de los granos de $\mathrm{Cu}_{2} \mathrm{~S}$, son mezclas de cobre, azufre, plomo y oxígeno, posiblemente un compuesto de $\left(\mathrm{Cu}_{2} \mathrm{~S}+\mathrm{PbO}_{2}\right)$. Ocasionalmente, la microestructura de la matriz exhibe gotas muy pequeñas de cobre puro y de plata pura formadas dentro de la fase de $\mathrm{Cu}_{2} \mathrm{~S}$. Esporádicamente, estos dos metales puros han crecido lado a lado dentro de la matriz. El fondo del pan es primeramente una escoria de silicato de plomo $\left(\mathrm{PbSiO}_{4}\right)$ con un componente menor de silicato de calcio $\left(\mathrm{CaSiO}_{3}\right)$, mezclado con tierra y pequeñas piedras.
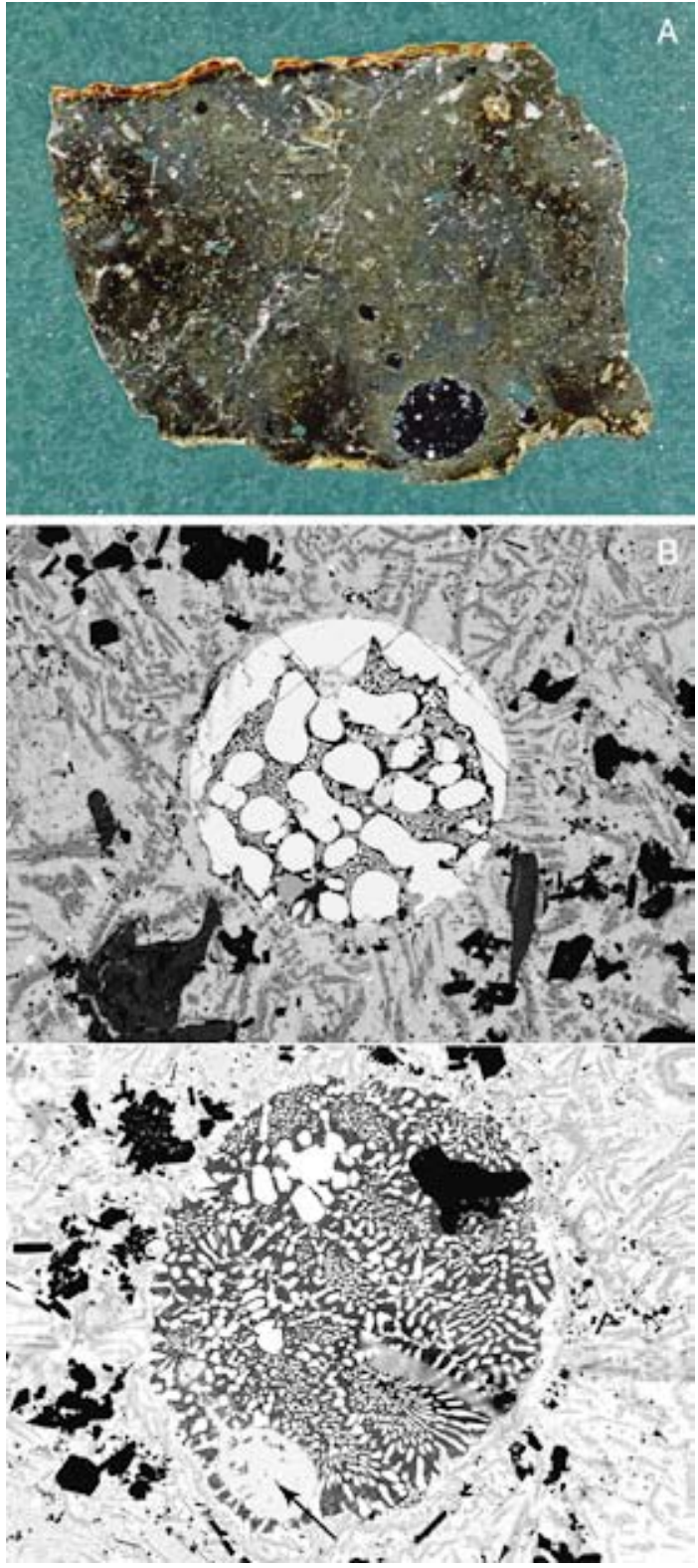

Figura 20. A) Muestra de una escoria cristalina de plomo con grandes glóbulos a la vista. B) Dos imágenes de electrones retro-dispersados de la escoria mostrada en la Figura 20a, tomados con un microhaz electrónico (EPMA). Aumento: 150. La fotomicrografía superior muestra un glóbulo cuya primera fase -galena- está rodeada de una pequeña fracción por volumen del microconstituyente eutéctico. La fotomicrografía de abajo está compuesta completamente por el microconstituyente eutéctico con un rasgo óvalo de plata pura (ver la flecha) creciendo dentro del eutéctico.

Figure 20. A) Sample of crystalline lead slag showing large globules. B) Two backscattered electron images of the slag shown in Figure 20a, taken with an electron probe microanalyzer (EPMA). Magnification: 150. The upper photomicrograph shows a globule in which the primary phase-galena-is surrounded by a small volume fraction of eutectic microconstituent. The lower photomicrograph is composed entirely of the eutectic microconstituent with an ovalshaped feature of pure silver (indicated by the arrow) growing within the eutectic. 
Se puede caracterizar el pan como una escoria, pero una escoria cristalina, no vitrificada. No hay un trazo de vidrio en la mezcla de materiales que compone el pan. Sin embargo, la escoria contiene varios componentes que fueron derretidos antes de solidificarse. De esta manera, el pan se presenta como el producto de una fundición y no de una refinación. La mena primaria parece haber sido un sulfuro de cobre o una mezcla de óxidos y sulfuros de cobre. Dado que la fuente de las menas ubicadas en Pulac 050 fue el depósito geológico de menas polimetálicas de Pulacayo ( $\mathrm{Pb}-\mathrm{Ag}-\mathrm{Cu}-\mathrm{Zn}$ ), no sería improbable que las cargas de los hornos hayan contenido menas complejas de sulfuros de cobre y de plomo, las cuales formaron una asociación (mineral intergrowths). En cuanto a la plata, su baja concentración en la escoria señala que, muy probablemente, haya sido un componente de la mena de plomo.

Asimismo, el hecho de que tanto el óxido de plomo $\left(\mathrm{PbO}_{2}\right)$ como el silicato de plomo $\left(\mathrm{PbSiO}_{4}\right)$ estén presentes en el pan con un alto estado de oxidación sugiere que, durante una etapa del procesamiento, las menas estuvieron sujetas a un ambiente rico en oxígeno. Se trata quizá del resultado de un tostado parcial de una mena de sulfuro de cobre $\left(\mathrm{Cu}_{2} \mathrm{~S}\right)$, donde, como consecuencia de la pérdida de azufre durante el tostado, parte de la mena cambió a un óxido de cobre. Dentro del horno, expuesto a un ambiente reductor, este óxido se habría convertido más tarde en un cobre metálico.

Otro espécimen analizado, mostrado en la figura 20, es una pesada y densa escoria de plomo con grandes glóbulos (prills) que se puede detectar a simple vista. El material compacto de la matriz tiene igualmente una coloración gris-acero (fig. 20a). Las fotomicrografías de la figura 20b muestran unos glóbulos situados en la compleja matriz, compuesta de cuatro fases principales: la fase primaria y predominante es el silicato de plomo $\left(\mathrm{PbSiO}_{4}\right)$ que aparece de color gris claro en las micrografías; listones (laths) de $\mathrm{PbSiO}_{4}$, de una coloración gris-oscuro y que contienen impurezas de aluminio, hierro y zinc, se encuentran diseminados por toda la fase primaria; grandes cristales eubedral de color negro del feldespato de potasio y bario -el mineral hialófana $[\mathrm{K}, \mathrm{Ba}]\left[(\mathrm{Al}, \mathrm{Si}){ }_{4} \mathrm{O}_{8}\right]$ - está presente en una concentración más baja, y pedazos ovales de baritina, sulfato de bario $\left(\mathrm{BaSO}_{4}\right)$, dispersos en la matriz.

El glóbulo en la fotomicrografía superior exhibe material grande y grueso de una fase primaria (blanco en la micrografía) rodeado por una pequeña fracción por volumen del microconstituyente eutéctico. Microanálisis electrónicos determinaron la fase primaria como galena (PbS). Cristales de color gris y de forma de listones, asociados con el eutéctico, son sulfuros de cobre y de plomo (Cu-Pb sulfuros) que contienen una concentración menor de plata $(0,9 \mathrm{wt} \% \mathrm{Ag})$.

El glóbulo en la fotomicrografía de abajo está compuesto completamente por el microconstituyente eutéctico de dos fases (blanca y negra). La fase blanca es $\mathrm{PbS}$ que contiene aproximadamente 1,5-2wt\% Cu. La fase negra es un sulfuro de cobre y de plata $\left(\mathrm{Cu}_{2} \mathrm{~S}+\right.$ $\mathrm{Ag}_{2} \mathrm{~S}$ ), calcocita y argentita, en la cual el $\mathrm{Cu}_{2} \mathrm{~S}$ predomina (el análisis de la fase negra determinó su composición como 65,78wt\% Cu, 12,62wt\% Ag). El análisis de los elementos en el microconstituyente mismo, normalizado al $100 \%$, es como se observa en la Tabla 1 :

Tabla 1. Microanálisis electrónico del eutéctico de un glóbulo dentro de la matriz de una escoria de plomo. Table 1. Electron microanalysis of the eutectic microconstituent of a globule within the matrix of a lead slag.

\begin{tabular}{|c|c|c|}
\hline Elemento & \% por peso & \% por fracción atómica \\
\hline $\mathrm{Cu}$ & 36.4 & 40.9 \\
\hline $\mathrm{Pb}$ & 38.8 & 13.4 \\
$\mathrm{~S}$ & 18.1 & 40.2 \\
$\mathrm{Ag}$ & 6.5 & 4.3 \\
$\mathrm{O}$ & 0.3 & 1.2 \\
\hline
\end{tabular}

El análisis de un rasgo óvalo de color gris-claro que aparece en la microestructura del glóbulo cerca de su borde inferior (fig. 20b, ver la flecha) determinó su composición como plata pura, sin $\mathrm{Cu}, \mathrm{Pb}, \mathrm{y} \mathrm{O}$. El glóbulo de plata ha crecido dentro del eutéctico separándose del plomo y del cobre.

La presencia de baritina y de hialófana en la matriz de la escoria es significativa. Ha sido demostrado que la baritina es uno de los mejores fundentes para la fundición de menas de plomo, porque descompone los silicatos de plomo dejando el plomo en estado metálico (Kassianidou 2003). La hialófana ha sido identificada en escorias de la antigüedad clásica asociadas con la extracción de plata en un sitio de Río Tinto, España (Craddock et al. 1985) y en Monte Romero, Huelva, España (Kassianidou 2003).

El espécimen mostrado en la figura 20a es un subproducto de la fundición de galena que contenía una cierta concentración de sulfuro de plata. El objetivo de la fundición fue producir plomo derretido, enriquecido en plata. Durante la fundición el plomo actuaría reuniendo las impurezas presentes en las menas fundidas, dejando la plata mucho más pura. El espécimen de Pulac 050 descrito aquí es un subproducto intermedio, un material todavía compuesto por silicatos de plomo. 
Al final del procesamiento de extracción de plata de menas de plomo, el plomo enriquecido en plata generalmente se elimina en un horno de refinación por el proceso de copelación. En este proceso, el plomo es tostado en atmosfera oxidante para formar litargirio, el óxido de plomo ( $\mathrm{PbO}$ ), dejando la plata bastante pura (Lechtman 1976). Hasta el presente, no hemos identificado restos de litargirio en el sector de los hornos, a pesar de que el litargirio es uno de los productos principales de la copelación. Sin embargo, hemos reunido en el sector de los hornos varios restos de plomo que fueron derretidos.

\section{PULAC 050: UN SITIO PUNEÑO PARA EL PROCESAMIENTO DE MENAS Y METALES}

A manera de síntesis, los estudios realizados en el sitio Pulac 050 revelan que se trata de un complejo establecimiento productivo del Horizonte Medio, donde se encuentran representadas varias etapas en la producción de metales: preparación de la mena, fundición extractiva, refinación secundaria, y probablemente trabajo de los metales en los recintos excavados. Estudios en curso podrían revelar otras etapas, como la producción de aleaciones. La complejidad de los sectores metalúrgicos de Pulac 050, la cual se observa igualmente en los recintos R1 y R2 excavados, señala una coordinación de la producción, así como la presencia de especialistas. El sitio Pulac 050 se anuncia como un establecimiento productivo inédito para este período en el espacio surandino. Estamos frente a un caso de evidente centralización de la producción, el cual solo se observa mucho más tarde con los inkas, por ejemplo en Quillay (Argentina), Potosí-Porco (Bolivia), y durante el período de contacto (Potosí-Porco, Santa Isabel, Choroloque, en Bolivia). En este sentido, consideramos relevantes las semejanzas y diferencias con los hornos de reverbero coloniales del sitio de Porco (Van Buren \& Cohen, en este volumen) y aquellos recientemente registrados en la región de Santa Isabel, pero que sabemos conjugan tecnologías indígenas y europeas. ${ }^{12}$ Estas semejanzas y diferencias amplían el debate sobre la continuidad y la transferencia de saberes tecnológicos indígenas durante el período colonial.

La localización elegida para la instalación del sitio, a unos $10 \mathrm{~km}$ de la antigua mina Pulacayo, puede responder a múltiples factores: la necesidad de aprovisionamiento en leña (principalmente tola), la proximidad del río Escaramayu, el resguardo del rudo clima de altura, y la posibilidad de abastecimiento en piedra pómez, abundante en el citado río y en las colinas circundantes. La presencia de abundantes bloques de piedra pómez formatizados en todos los contextos estudiados de Pulac 050 señala su utilización en una o en varias etapas del proceso de producción de metales, pero que desconocemos todavía. Al respecto, Alonso Barba (1640) señala su uso indígena en las fases finales de la producción de objetos metálicos. ${ }^{13}$

En otra escala de la cuestión, los nuevos registros indican que la región de Pulacayo se constituyó durante el Horizonte Medio como un área de fuerte desarrollo cultural y económico, y no como se venía sosteniendo, un territorio marginal de los centros nucleares del altiplano circunlacustre y circumpuneño. Estos nuevos datos sugieren más bien que se trataba de un enclave productivo asociado con la producción de metales, vinculado desde la cultura material tanto con los valles de Yura (Lecoq \& Céspedes 1997; Céspedes \& Lecoq, 1998) como con la región de Quillacas (Michel López 2008), y más allá de estas, con el norte de Chile y, ciertamente, con Tiwanaku. Tanto las riquezas de sus minerales, como el dominio y el conocimiento de saberes minerometalúrgicos que poseyeron sus antiguos habitantes, sugieren la importancia de Pulacayo dentro de los procesos sociales que tuvieron lugar en el altiplano surandino durante este período y, en particular, en las dinámicas de interacción entre el altiplano circumpuneño y las áreas nucleares de Tiwanaku y San Pedro de Atacama.

Sin embargo, en Pulacayo es relevante tanto la escasa representatividad de materiales alóctonos en los sitios de producción metalúrgica estudiados, como la ausencia de establecimientos o colonias propiamente Tiwanaku. Se trata de una situación cercana a la observada en San Pedro de Atacama (Berenguer et al. 1980; Llagostera 1996; Torres \& Conklin 1995), y contraria a la observada en el altiplano boliviano y el norte de Chile (Berenguer \& Dauelsberg 1989; Albarracín-Jordán 1996; Michel López 2008). El registro arqueológico de Pulacayo se muestra coherente con el modelo de áreas internodales (Berenguer 2004; Nielsen 2006), una región que, más allá de constituirse como un espacio de circulación, fue también el escenario de encuentros e intercambios económicos, poblacionales y culturales -y quizás de desarrollo tecnológico- entre las diferentes sociedades que poblaron los Andes del sur.

RECONOCIMIENTOS Nuestros agradecimientos a Verónica Cereceda de la Fundación ASUR (Antropólogos del Sur Andino), Sucre, Bolivia, y a la Fundación Selz de Nueva York, por su apoyo tanto logístico como financiero para la realización de esta investigación. Agradecemos también a la Lic. Jimena Montero por su calificada administración del proyecto, así como por su trabajo en terreno. Agradecemos al Dr. Axel Nielsen por sus consejos; al Dr. Larry Kaufman por su 
colaboración en determinar, por medio del programa de computadora ThermoCalc, las temperaturas de vitrificación de muestras de tierra y cerámica del sector de los hornos en Pulac 050, y al Dr. Nilanjan Chatterjee por su ayuda en la interpretación de los microanálisis electrónicos de las muestras de escoria. Agradecemos finalmente a la comunidad de Escara por haber autorizado y acompañado el desarrollo de las investigaciones en Pulac 050.

\section{NOTAS}

${ }^{1}$ Brazales arqueológicos semejantes, cuya función no ha sido aún establecida, se encuentran solamente en Bolivia, el noroeste de Argentina y el norte de Chile.

${ }^{2}$ Ref. PU-1. Geochron Laboratories, fechado realizado por ASUR (Antropólogos del Sur Andino).

${ }^{3}$ Las evidencias sobre este tipo de actividades en la región son escasas y se limitan a los estudios de casos de Lípez (Nielsen \& Angiorama 2009), Porco (Van Buren 2003) y Potosí (Cruz \& Absi 2009). En una escala más amplia, se desarrollaron análisis sobre la tecnología metalúrgica en la macrorregión, tanto prehispánica como colonial (Van Buren \& Mills 2005).

${ }^{4}$ P050 A UR1 R1, UR055 Paléotropique, Laboratoire des Mesures Carbone 14 UMS2572.

${ }^{5}$ P050 B UR1 R3, UR055 Paléotropique, Laboratoire des Mesures Carbone 14 UMS2572.

${ }^{6} \mathrm{Al}$ no constatar testimonios materiales que indiquen una ocupación anterior, o una secuencia de ocupaciones, una de las explicaciones de este fechado estaría en el efecto old-wood

${ }^{7}$ Como por ejemplo, en el Arte de los metales de Alonso Barba (1640).

${ }^{8}$ PaleoResearch Institute, Golden, Colorado. Technical Report 10-51, April 2010

9 Se utiliza el verbo "derretir" en lugar de "fundir" para distinguir entre fundir "to smelt an ore" y derretir "to melt something, such as a metal or a ceramic."

${ }^{10}$ Entre otros, Alonso Barba (1640: 228). $\left(\mathrm{Cu}_{2} \mathrm{~S}\right)$.

${ }^{11}$ La contribución de cobre pudo haber venido de la matriz

${ }^{12}$ En esta región se identificaron varios sitios metalúrgicos con hornos de reverbero semejantes a los descritos por Alonso Barba (1640). Estos sitios están siendo actualmente estudiados por F. Téreygeol, I. Guillot y P. Cruz.

13 "[...] Piedra pómez, volcánica esponjosa, frágil de color agrisado, y fibrosa que raya el vidrio y sirve para desgastar y pulir" (Alonso Barba 1640: 290).

\section{REFERENCIAS}

Albarracín-Jordán, J., 1996. Tiwanaku. Arqueología regional y dinámicas segmentarias. La Paz: CID-Plural.

Alonso BarBa, A., 1640. Arte de los metales. Sucre: Imprenta del Reyno. Bachmann, H-G., 1982. The identification of slags from archaeological sites. Occasional Publication $\mathrm{N}^{\circ}$ 6. London: Institute of Archaeology.

Berenguer, J., 2004. Caravanas, interacción y cambio en el desierto de Atacama. Santiago de Chile: Sirawi Ediciones.

Berenguer, J. \& P. Dauelsberg, 1989. El norte grande en la órbita de Tiwanaku (400-1200 DC). En Culturas de Chile: Prebistoria, J. Hidalgo, V. Schiappacasse, H. Niemeyer, C. Aldunate \& I. Solimano, Eds., pp. 129-180. Santiago: Editorial Andrés Bello. Berenguer J.; V. Castro \& O. Silva, 1980. Reflexiones acerca de la presencia de Tiwanaku en el Norte de Chile. Estudios Arqueológicos 5: 81-93, Santiago de Chile.
Céspedes, R., 2000 Ms. La Cueva de Pulacayo. Sucre: Antropólogos del Sur Andino.

Céspedes, R. \& P. Lecoq, 1998. El Horizonte Medio en los Andes Meridionales de Bolivia (Potosí). En Los desarrollos locales y sus territorios. Arqueología del NOA y sur de Bolivia, B. Cremonte, Ed., pp. 103-130. San Salvador de Jujuy: Universidad Nacional de Jujuy.

Costa Junqueira, M. A., 2003. Análisis bioantropológico de la Colección Pulacayo (Altiplano Boliviano). Informe Año 2 Proyecto FONDECYT N ${ }^{\circ} 1010735$.

Craddock, P. T.; I. C. Freestone, N. H. Gale, N. D. Meeks, B. RothenberG \& M. S. Tite, 1985. The investigation of a small heap of silver smelting debris from Río Tinto, Huelva, Spain. En Furnaces and Smelting Technology in Antiquity, British Museum Occasional Paper No 48, P. T. Craddock \& M. J. Hughes, Eds., pp. 199-217. London: British Museum Research Laboratory.

Cruz, P., 2010. Tumbas, metalurgia y complejidad social en un páramo del altiplano surandino. Pulacayo, Bolivia, primer milenio d. C. Revista Andina 49: 71-104, Cusco.

Cruz, P. \& P. ABsi, 2009. Cerros ardientes y huayras calladas. Potosí antes y durante el contacto. En Mina y metalurgia en los Andes del Sur. Desde la época prehispánica hasta el siglo XVII, P. Cruz \& J. J. Vacher, Eds., pp. 91-120. Sucre: Institut de Recherche pour le Développement / Instituto Francés de Estudios Andinos.

KASSIANidOU, V., 2003. Early extraction of silver from complex polymetallic ores. En Mining and Metal Production, P. Craddock \& J. Lang, Eds., pp. 198-206. London: The British Museum Press.

Kaufman, L., 2001. Computational thermodynamics and materials design. CALPHAD 25: 141-161.

Lechtman, H., 1976. A metallurgical site survey in the Peruvian Andes. Journal of Field Archaeology 3 (1): 1-42.

LeCoQ, P. \& R. CÉSPEDES, 1997. Nuevos datos sobre la ocupación prehispánica de los Andes Meridionales de Bolivia (Potosí). Cuadernos 9: 111-152, San Salvador de Jujuy.

Llagostera, A., 1996. San Pedro de Atacama: Nodo de complementariedad reticular. En La integración surandina cinco siglos después, X. M. Albó, J. Anatia, L. Hidalgo, L. Núñez, A. Llagostera, M. I. Remy \& B. Revesz, Eds., pp. 17-42. Antofagasta: Universidad Católica del Norte.

Michel López, M., 2008. Patrones de asentamiento precolombino del altiplano boliviano. Lugares centrales de la región de Quillacas, Departamento de Oruro, Bolivia. Tesis doctoral, Uppsala University, Uppsala.

Nielsen, A., 2006. Estudios internodales e interacción interregional en los Andes circumpuneños: Teoría, método y ejemplos de aplicación. En Esferas de interacción prebistóricas y fronteras nacionales modernas: los Andes Sur Centrales. H. Lechtman, Ed., pp. 29-63. Lima / New York: Instituto de Estudios Peruanos / Institute of Andean Research.

Nielsen, A. \& C. Angiorama, 2009. Los metales de Laqaya: aproximación a la metalurgia prehispánica tardía del norte de Lípez (Potosí, Bolivia). En Mina y metalurgia en los Andes del Sur. Desde la época prebispánica hasta el siglo XVII, P. Cruz \& J. J. Vacher, Eds., pp. 121-138. Sucre: Institut de Recherche pour le Développement / Instituto Francés de Estudios Andinos.

Téreygeol, F. \& P. Cruz, 2010. Der silber bergwerk von Potosi: neue daten über die archäologischen. Der Anschnitt, Bochum: Deutschen Bergbau-Museum (en prensa).

Torres, C. \& W. Conklin, 1995. Exploring the San Pedro de Atacama / Tiwanaku relationship. En Andean Art: Visual Expression and its Relation to Andean Beliefs and Values, P. Dransart, Ed., pp. 78-108. Avebury: Aldershot.

VAN BurEn, M., 2003. Un estudio etnoarqueológico de la tecnología de fundición en el sur de Potosí, Bolivia. Textos Antropológicos 14 (2):133-148. La Paz: Universidad Mayor de San Andrés.

Van Buren M. \& B. Mills, 2005. Huayrachinas and Tocochimbos: Traditional smelting technology of the southern Andes. Latin American Antiquity 16 (1): 3-25. 
